\title{
Experimentelle Untersuchungen über den Einfluß höherer Temperatur auf Morphologie und Cytologie der Algen.$$
\text { Von }
$$ \\ Otto Hartmann (Graz).
}

Mit 3 Tafeln und 2 Textabbildungen.

(Eingegangen am 27. Januar 1918.)

Inhaltsiibersicht. Selte

Einleitung ..................... . . . . . . . . . . . . .

Material und Methode. . . . . . . . . . . . . . . 592

A. Spezieller Teil . . . . . . . . . . . . . . . . . . . . 594

I. Conjugatae:

1. Spirogyra (Spir. tenuissima, varians, grevilleana, nitida, Weberi) . . . . . . . . . . . 594

2. Zygnema ............... . . 613

3. Mougeotia ................... . 614

4. Desmidium . . . . . . . . . . . . 616

II. Protococcoideae:

5. Protococcus . . . . . . . . . . . 616

III. Siphoneae:

6. Vaucheria . . . . . . . . . . . . 618

IV. Confervoideae:

7. Oedogonium . . . . . . . . . . . . . .619

8. Microspora . . . . . . . . . . . . . 620

9. Ulothrix . . . . . . . . . . . . . . 621

10. Stigeoclonium................621

V. Bacillariaceae:

11. Tabellaria ................623

12. Diatoma . . . . . . . . . . . . . . . 623

13. Cymbella . . . . . . . . . . . . 624

14. Synedra . . . . . . . . . . . . . . . 625

15. Navicula . . . . . . . . . . . . . . 625

VI. Cyanophyceae:

16. Oscillatoria . . . . . . . . . . . . . 626

B. Zusammenfassung der allgemeinen Resultate . . . . . . 630

C. Literaturverzeichnis . . . . . . . . . . . . . 636

D. Tafelerklärung . . . . . . . . . . . . . . . 610

\section{Einleitung.}

Im Anschluß an meine Experimente über den Einfluß der Temperatur auf die Größe der Chlorophyllkörner, die den $Z_{w e c k}$ verfolgten, auch bei diesen Zellgebilden eine der Kernplasmarelation entsprechende Temperaturvariabilität festzustellen, kultivierte ich auch eine Spirogyra- 
Art bei hoher und tiefer Temperatur. Da zeigte sich nun eine Menge interessanter Erscheinungen, besonders was die Größe, Gestalt und Anordnung der Chlorophyllbänder betraf, die ich l. c. schon kurz besprochen habe, daß ich beschloß, den Einfluß hoher Temperatur auf Algen überhaupt einer genaueren Untersuchung im Hinblick auf Morphologie, Cytologie und Zellphysiologie zu unterwerfen, deren Resultate nun vorliegen. Es kommt mir hierbei nicht darauf an, den Einfluß der Temperatur auf die absolute Wachstumsgeschwindigkeit usw. im Sinne der R.-G.-T.-Regel und Temperaturkoeffizienten zu untersuchen und zu diskutieren. Bemerkungen über diese: Verhältnisse wie über die neueren Theorien von $\mathrm{Black}$ mann und $\mathrm{P} \ddot{\mathrm{u}}$ ter findet man in meiner Arbeit (37). Auch die Verhältnisse der Kernplasmarelation sollen nicht besonders studiert werden, da sich die Algen, weil ihr Plasma nur einen mehr minder geringen Teil der Zelle erfüllt, demnach von einèr Kernzellrelation eigentlich gesprochen werden müßte, zu solchen Experimenten wenig eignen. Man könnte ja allerdings daran denken, daß Zellvolumen und Plasmavolumen ihrerseits offenbar in einem bestimm. ten Verhältnis stehen und damit durch die Beziehung des Kernvolumen auf das Zellvolumen indirekt auch eine solche auf das Plasma gegeben sei. Aber dies gilt nur für Versuche, die bei Temperaturkonstanz bzw. bei nur geringer Variation dieses Faktors angestellt werden. Denn bei hoher Temperatur findet, wie ich bei Phanerogamen eingehend studiert habe (37), eine außerordentlich starke Plasmareduktion statt, während die Zellgröße unverändert bleibt oder gar zunimmt. Dasselbe gilt nun auch für Algen, mithin entspricht bei hoher Temperatur einer bestimmten Zellgröße weniger Plasmamasse als bei niederer, womit sich die Verhältnisse offenbar komplizieren, da ja Plasmavolum und Zellvolum einen Einfluß auf die Kerngröße haben. Soll nun demgemäß auch die Kernplasmarelation und Kernzellrelation nicht genauer zahlenmäßig untersucht werden, so wird doch auf das Verhalten der Kerngröße, wie es bei unmittelbarer Betrachtung sich zu erkennen gibt, oft zurückzukommen sein. Es haben nämlich meine Experimente an Algen zu prinzipiell denselben Resultaten diesbezüglich geführt, wie bei höheren Pflanzen (37) und wie sie von anderen Autoren und mir bei Protozoen und Metazoen gewonnen wurden, womit die prinzipielle Gleichartigkeit der experimentellen Beeinflussung cytologischer Verhältnisse und Gleichgewichte durch die Temperatur im gesamten Organismenreiche als erwiesen zu betrachten ist.

Im Vordergrunde des Interesses vorliegender Untersuchung steht die Gestalt, Anordnungsweise und Größe der Chromatophoren und der Kerne wie überhaupt die feinere cytologische Beschaffenheit, wobei auch eingehender die zellphysiologische Wirksamkeit höherer Temperatur vom allgemeinen Gesichtspunkte aus erörtert werden soll. 
den Einfluß höberer Temperatur auf Morphologie und Cytologie der Algen. 591

Uber den Einfluß der Temperatur auf morphologisch-cytologische Verhältnisse bei Algen liegen, soweit mir bekannt, systematische, experimentelle Untersuchungen kaum vor, wohl aber gelegentliche $\mathrm{Be}$ obachtungen und Untersuchungen an Freilandgewässern. Auf die Verhältnisse der sog. Cyclomorphose bzw. Saisondimorphismus, wie sie zumal bei Planktonalgen beobachtet wurden, gehe ich nicht weiter ein, da diese Verhältnisse nach den Ursachen nicht genau aufgeklärt scheinen ${ }^{1}$ ). Besser untersucht erweist sich Ceratium, bei dem Temperatur und Chemismus als gestaltbestimmend erkannt sind und auch ein Parallelismus mit cytologischen Verhältnissen sich hat nachweisen lassen (vgl. Hartmann 34). Weitere Angaben über den EinfluB der Temperatur auf Algen in morphologischer Beziehung habe ich bei Ray $B$, Br. Schröder and Wille gefunden.

Die Wirkung anderer Faktoren hat jedoch eingehendere Berücksichtigung gefunden.

- Vor allem ist der Einflu B des Che mis mus und Milieus überhaupt studiert worden. Guyer erkannte ihn als bedeutsam für die Gestalt von Ceratium hirundinella. Beobachtungen von Schultz und anderen beziehen sich auf Veränderungen der Algen in Brackwasser. Uber den allgemeinen Milieueinfluß berichtet Desroche, dem es gelang, eine experimentelle Transformation von Vaucheria terrestris in Vauch. geminata durchzuführen, mithin beide Formen als milieubedingt nachzuweisen. Uber den Einfluß der Nährlösung findet man Angaben bei Techet: Stigeoclonium zeigt nach Klebs auf Agar-Agar bzw. in Nährlösungen in feuchter Kammer sehr verschieden starke Ausbildung de: Verzweigungen. Den Einfluß der Durchlüftung, Sauerstoffgehalt, Wasserbewegung studierten Chambers, Karsten (Skeletonema costatum), Klebs (verschiedene Ausbildung der Haare von Stigeoclonium in Abhängigkeit von der Wasserbewegung). Besonders eingehende Untersuchungen über die morphologische Wirkung von Salzen verdanken wir O. Richter. Die Anpassung an oft erstaunlich hohen Koshsalzgehalt (bei Tetraspora explanata bis $13 \%$ !) ist bei verschiedenen Algen mit Zell- und Membranverdickung (Anabiena, Zygnema) und mit mannigfachen Verkrüppelungen und Verbiegungen der Zellen verbunden (Mougeotia), welche Veränderung bei letzterer Alge jedoch mit der Vollendung der Anpassung wieder verschwinden. Verkrüppelungen und Involutionsformen beobachtet auch Andreesen bei Desmidiaceen.

So interessant diese morphologischen Einflüsse des Chemismus sind, so haftet ihnen allen in den meisten Fällen doch ein mehr minder pathologischer Ciarakter an. Es handelt sich meistens um schwere Störungen,

1) Vgl. Schröder u. Vogler (Fragilaria), Lozeron (Asterionella). Lit. bei Steuer. 1910. 
die sich in Verkrüppelungen usw. bemerkbar machen und die in vielen Fällen überhaupt nicht mehr, in anderen nur nach langer Zeit der Regulationsprozesse überwunden werden können. Es handelt sich mit anderen Worten einfach um mehr minder vollkommene Anpassungen an schädliche, giftige Substanzen. Ganz anders liegen nun die Verhältnisse bei den Te mpera tur experi men ten, insofern sie sich in bestimmten Grenzen halten und auch nicht allzu stenotherme Arten in Betracht kommen. Die Temperatur ist ein Faktor, der den Organismen einmal immer gegeben ist und auch in weiter Amplitude physiologischen Schwankungen unterworfen ist. Denn wenn auch extremere Temperaturen schädigend wirken, bzw. Veränderungen veranlassen, so tun sie es nicht so sehr im Sinne pathologischer Stoffwechselstörung, sondern mehr im Sinne einer Gleichgewichtsverschiebung der einzelnen Stoffwechselkomponenten oder überhaupt einer abnormen Beschleunigung sonst normaler Prozesse. In der Temperatur wird nur eine der Bedingungen jedes Lebensprozesses verändert, nicht aber ein neuer Faktor, der selbst in das normale Stoffwechselgetriebe eingreift, geschaffen, wie das z. B. bei chemischen Einflüssen meistens stattfindet. Darin liegt eine Bedeutung und Ausnahmestellung.der Temperaturexperimente anderen Untersuchungen gegenüber, sobald natürlich von direkt letalen Temperaturen abgesehen wird. Gerade die oft verschieden starke Beschleunigung verschiedener Stoff wechselund morphologischer Prozesse durch Temperaturerhöhung gestatten nun aus den gegebenen morphologisch erkennbaren Veränderungen Rückschlüsse auf zellphysiologische Vorgänge bzw. die Bedeutung und Funktion verschiedener Zellorgane zu machen (vgl. Hartmann 35, 36, 37). Auch werden gewisse Prozesse, die sonst ihrer geringen Geschwindigkeit und Intensität halber sich morphologisch nicht erkennbar manifestieren, bei höherer Temperatur infolge gesteigerter Intensität direkt im mikroskopischen Bilde sichtbar (z. B. die Chromatinemission). Endlich ist es oft möglich, interessante physikalische Zustandsänderungen bei hoher Temperatur morphologisch festzustellen, wie überhaupt die Temperatur darin eine Ausnahmestellung einnimmt, da $B$ sie als fundamentale Lebensbedingung in ihren Veränderungen oft tiefgreifende nichtsdestoweniger innerhalb der Grenzen des Physiologischen bleibende, morphologische und physiologische Veränderungen bewirkt.

\section{Material und Methode.}

Da die meisten Versuche im ersten Frühjahr gemacht wurden, so waren für die Kältekulturen, deren Temperaturen sich zwischen 3-6 ${ }^{\circ}$ bewegten, keine besonderen Vorbereitungen erforderlich. Die im Freien bei oben angegebenen Temperaturen gesammelten Algenwatten, die of $t$ 
den Einfluß höherer Temperatur auf Morphologie und Cytologie der Algen. 593

überhaupt nur eine Form enthielten, wurden entweder gleich fixiert, oder einige Tage bei niederer Temperatur gehalten. Für die Versuche bei hoher Temperatur erwiesen sich die verschiedenen Gattungen, ja selbst Arten derselben Gattung, sehr verschieden resistent und geeignet. Während Diatoma hiemale nur etwa $20-21^{\circ} \mathrm{C}$ verträgt, konnte $C y m$ bella sehr gut mehrere Tage bei $31^{\circ} \mathrm{C}$ gehalten werden. Letztere Temperatur war es auch, bei der die Mehrzahl aller untersuchten Algen kultiviert wurde. Die Kultur erfolgte im Thermostaten bei mittlerer Tageslichtbelouchtung in flachen Glasschalen, wobei natürlich die Algen zunächst mit kaltem 'Wasser hineingestellt wurden, so da $\beta$ jeglicher Temperatursturz vermieden wurde. Jeden Tag nun - bei manchen Versuchen auch öfter - und zwar meist am Vormittage, wurde etwas Material den Kulturen entnommen und sofort fixiert. Die Kulturdauer betrug meist nur 2-4 Tage, da innerhalb dieses Zeitraumes sich alle studierten morphologischen Veränderungen vollständig ausbilden, viele Algen auch eine wesentlich längere Kulturdauer nicht vertragen. Die Fixierung erfolgte 24 Stunden in Chromessigsäure, worauf ebensolange ausgewaschen und je nach dem Objekte einige Stunden bis einen Tag in Hämalaun gefärbt, hierauf in $10 \%$ Glyzerin übertragen und dieses in offener Glasschale bei $30^{\circ}$ langsam konzentriert wurde. Einschlu $B$ in reinem Glyzerin.

Die zusammengehörigen Mikrophotographien sind nach solchen Präparaten bei jeweils derselben Vergrößerung hergestellt, ebenso die Zeichnungen. Uberhaupt sind alle cytologischen Angaben auf die Untersuchung in obigem Sinne behandelten, fixierten Materials aufgebaut.

Im folgenden gebe ich die Resultate meiner Untersuchungen systematisch nach den Objekten geordnet, wobei gleichzeitig auch allgemeine zellphysiologische Probleme, insofern sie bei einem gegebenen Objekte besonders gut zu studieren waren, besprochen werden sollen. Am Schlusse wird ein allgemeiner Teil die Zusammenfassung der allgemeinen Ergebnisse bringen.

Die Bestimmung der Arten ist nichtimmerexakt, da Fortpflanzungsstadien usw. meist nicht zur Verfügung standen. Auf eine genaue Identifizierung konnte, abgesehen vom Umstande, da $B$ es sich nur um die experimentelle Beeinflussung gegebener Formen handelte, um so eher verzichtet werden, als die Mikrophotographten über den Habitus und seine experimentelle Veränderúng genügenden Aufschlu $B$ geben. 


\title{
A. Spezieller Teil.
}

\author{
1. Spirogyra.
}

a) Spirogyra tenuissima Kützg.

(Taf. XVI, Abb. 1-4; Taf. XVIII, Abb. 41-46.)

Zellen mit gefalteten Querwänden. Breite etwa $14 \mu$. Ein breites Cnlorophyllband mit fünf bis neun Umgängen. Diese Art wurde am 21. Februar in einem kleinen Teiche zusammen mit massenhaft Mougeotia gesammelt und 4 Tage lang bei $30^{\circ} \mathrm{C}$ kultiviert.

Ich werde bei dieser Art die Veränderungen genau besprechen, um mich bei den nachfolgenden, die in manchen Punkten ähnliche Verhält. nisse darbieten, kürzer fassen zu können. Die übersichtliche und verständliche Darstellung der vielfach komplizierten Verhältnisse läßt Wiederholungen bei dieser ersten zur genauen Besprechung gelangenden Art unvermeidlich erscheinen.

Die bei tiefer Temperatur $\left(4-5^{\circ} \mathrm{C}\right.$, Taf. XVI, Abb. 1) reichlich gezackten und vielStärke enthaltenden Chlorophyllbänder, deren fixiertes Stroma dicht und reich granuliert erscheint, verlieren schon nach eínem Tage in der hohen Temperatur alle Stroma- und einen großen Teil der Pyrenoidstärke, über deren.physiologische Unterschiede man Kle bs (47) vərgleichen möge. Die Körnelung der Bänder macht ebenfalls einer mehr homogenen Struktur Platz, die Zähnelung der Bänder ist viel geringer und infolge des starken Streckungswachstumes der Zellen nach jeder Teilung, dem die Substanzproduktion nicht nachfolgen kann, sind die Windungen auch mehr gestreckt und weniger zahlreich. Nach zwei Tagen ist die Randlappung der Bänder nur mehr ganz schwach, die Konturen also fast gerade, infolge starker Streckung und Substanzschwundes sind die Bänder auch viel weniger dicht und massig. Die Zellänge ist oft sehr bedeutend, die Windungsanzahl der Bänder stark herabgesetzt. Statt etwa zehn Windungen bei langen Zellen in der Kälte finden sich nur fünf bis sechs. Am 3. und 4. Tag haben die Veränderungen ihr Maximum und ihren Abschluß erreicht (Abb. 2-4). Auf diese Verhältnisse müssen wir daher näher eingehen.

Infolge des auf die Zellteilung rapide und stark einsetzenden Strekkungswachstums, dem genügende Neuproduktion plasmatischer Substanz nicht parallel geht, ist das Chlorophyllband oft fast gerade und parallel der Längsachse der Zelle eingestellt, trotzdem erreicht es oft nicht das beiderseitige Zellende ${ }^{1}$ ). Die Bänder sind schmal, mit geradem

1) Die Streckung des Bandes ist bei anderen Arten oft viel stärker ausgebildet (vgl. Hartmann 38) und ebenso wie die re!ativ zur Zelliänge abnehmende Länge des Bandes nicht auf Kontraktion zurückzuführen - diese tritt nur in den ersten Stunden in der hohen Temperatur als Reizeffekt auf und geht dann wieder zurück - wie das Famitzin (1866, zit. nach Gerassimow) in Dunkelkulturen beobachtet hat. In meinen Versuchen ist die Ursache eine 
Rande und weniger band- als mehr walzenförmig, was auf eine Zunahme des Flüssigkeitscharakters hinweist. Die Windungen, die etwa noch erkennbar sind, weisen einen mehr eckigen Charakter auf, wie das Abb. 2, die noch nicht das äuBerste Stadium der Veränderungen darstellt, erkennen läßt. Dieses stellt erst Abb. 3 dar, wo ausnahmsweise eine Verdoppelung des Bandes ${ }^{1}$ ) stattgefunden hat, über deren vermutliche Ursachen gleich gehandelt werden soll. Die Genese ist offenbar folgende : Am Ende des am 3. oder 4. Tage der Wärmekultur offenbar schon ziemlich weichen und leicht zerreißbaren Bandes findet man öfter ein mehr minder großes Stück abgebrochen. Die Ursache ist vielleicht in der Spannung des wenig resistenten Gebildes oder in Abschnürung infolge geänderter Kohäsionsverhältnisse zu finden ${ }^{2}$ ). Dieses auf diese Weise selbständig gewordene Bandstück wächst nun in die Länge ${ }^{3}$ ) und bildet bald ein dem ursprünglichen gleich langes Gebilde. Die beiden Ränder überkreuzen sich geometrisch ein- bis zweimal und verschmelzen an solchen Stellen auch oft (wieder ein Zeichen ihrer stark flüssigen Konsistenz). Interessant ist, da $B$ das auswachsende Bandfragment offenbar durch eigene Aktivität eine Schraubenform annimmt. Es kommt also wohl den Chromatophoren und auch Fragmenten von ihnen die Fähigkeit $\mathrm{zu}$, die arteigene und charakteristische Anordnung und Gestalt aus eigener Aktivität herzustellen, also ohne ordnende Hilfe des Plasmas. Darauf deutet auch hin, daB das auswachsende Band sich mit seinem, dem Zellende proximalen Ende in mehrere Lappen verbreitert und scheinbar dadurch sich an dieser Stelle einen Fixpunkt für das Wachstum und die Windungsbildung schafft4). Diese eigenartige, übrigens

abnorme Zellstreckung bzw. die große Geschwindigkeit des Zellwachstums nach der Zellteilung, wie eine solche übrjgens nach $\mathrm{Zach}$ arias (Bot. Zeitg.) auch in Dunkelkulturen vorkommt. Nach OItmann ruft auch überreiche Belichtung bei Ektokarpeen Utberverlängerung der Zellen hervor. Da Licht und Temperatur in höheren Intensitäten die dissimilatorisohe, also. Streckenwachstum be: dingende Phase des Zellstoffwechsels beschleunigt, so sind diese Ergebnisse erklärlich, während die Kontraktion bei Famitzin als Reizreaktion außerhalb der hierhergehörigen Fragen steht.

1) Vgl dazu Kasanowski bei Spirog. Nawaschini nov. sp.

2) Typischen Chromatophorenzerfall unter experimentellen, zum Teil allerdings pathologischen Bedingungen beobachtet Andreesen bei Cosmarium, Matrouchot u. Molliard bei Stichococcus in Inulin.

3) DaB Bandstücke zu ganzèn Bändern auswachsen können, hat Wisselingh in seinen Zentrifugenversuchen sogar in kernlosen Zellen beobachtet und ich kann das auf Grund obiger Experimente bestätigen.

4) Ich bemerke die Wahrscheinlichkeit der aktiven Gestaltung des Bandes, dessen Wachstum, wie wir durch Kolkwitz wissen, sowohl intercalar als an der Spitze erfolgen kann, deshalb, weil nach Sch midt an zentrifugierten Zellen ein passives Anortbringen der verlagerten Chromatophoren durch Plasmafäden stattfindet, während in unserem Falle das Band offenbar schon während des Wachstums in seine typische Spiralform hineinwächst. 
ziemlich seltene Bandverdoppelung läßt sich oft in vielen hintereinander liegenden Zellen eines Fadens nachweisen, was darauf hindeutet, daß das offenbar durch eine gemeinsame, äußere oder innere, Ursache bedingt ist. Am selben Faden kommen dann aber auch natürlich normale Zellen vor.

Charakteristisch für die physikalische Beschaffenheit der Chlorophyllbänder in der Wärme ist es, daß an jenen Stellen, an denen die Plasmafäden sich anheften, offenbar durch den durch sie ausgeübten Zug das Chromatophorenstroma lappig vorgezogen erscheint; was man in gleichem $\mathrm{Maße}$ in der Kälte niemals beobachtet. Nach längerer Kultur in hoher Temperatur, wenn die Bänder schon mehr walzenförmig sind, beobachtet man das nicht mehr, offenbar hat dann durch Wasserabgabe eine Zunahme der Festigkeit stattgefunden.

Es erübrigt nun nur noch einen kleinen Uberblick über die Art und Weise der Zellstreckung, Teilung usw. in der Wärme zu geben, da wir hier die Ursachen der eigentümlichen Gestaltveränderung der Chromatophoren zu suchen haben. Die Wachstumsprozesse finden nun, wie schon erwähnt, nach jeder Teilung offenbar mit solcher Intensität statt, daß der Aufbau der lebenden Substanz, besonders der Chromatophoren damit nicht Schritt halten kann. Der Stoffumsatz ist nämlich in der Wärme nicht nur beschleunigt in dem Sinne, daß alle Prozesse eine gleich mäßige Erhöhung ihrer Intensität orfahren, sondern die Okonomie des Stoffwechsels ist - worauf später noch einzugehen sein wird ganz bedeutend herabgesetzt (vgl. Hartmann 36, 37, Wasniewsky, Harder), d.h. es wird relativ und absolut viel mehr dissimiliert und veratmet, wodurch es klar ist, daß nicht Aufbau neuer plasmatischer Substanz parallel dem Zellwachstum erfolgen kann, sondern der Abbau zu osmotisch wirksamen, also wachstumsfördernden, Stoffen überwiegt. Auch nach Erlangung der definitiven Zellänge, die in der Wärme oft bedeutend die in niederer Temperatur übertrifft, findet jedoch die Zelle offenbar nicht Zeit zur Neubildung, d. h. zur Vermehrung der lebenden Substanz, denn die Stoffwechselbilanz ist eben - das ist für hohe Temperaturen allgemein charakteristisch - dauernd zuungunsten der assimilatorischen Phase verschoben, also unökonomisch gestaltet (vgl. die oben zitierte Literatur).

So muß also dieselbe Chromatophorenmasse, die außerdem durch Dissimilation substanzärmer geworden ist, die in der Kälţe die Hälfte der Zelle ausfüllte, nach der Teilung eine ganze Zelle erfüllen, nach der nächsten Teilung noch mehr usw., so daß sich aufs einfachste die $\mathrm{Zu}$ nahme der Streckung der Bänder erklärt.

Nach 2-3 Tagen ist auf diese Weise und durch dauernde starke Dissimilation offenbar überhaupt die lebende Masse der Zelle so stark reduziert, daß nach einer erneuten Teilung kein so intensiver oder über- 
haupt kein Wachstum der Zellgröße mehr stattfindet. .Das Plasma ist offenbar schon so stark reduziert, daß es nicht mehr durch osmotisch wirksame Stoffe den für das Zellwachstum nötigen Druck zustande bringen kann. Dazu kommt noch, daß offenbar der Widerstand, den die Zellmembran jetzt dem weiteren Streckungswachstum durch Dehnung entgegensetzt, bedeutend größer ist. Denn infolge des raschen Wachstums bisher ist es wohl nicht so sehr zur Neubildung und Einlagerung neuer Membransubstanz gekommen, als zu rein passiver Dehnung ${ }^{1}$ ), was man aus der Abnahme der Membrandicke erschließen kann. Durch das Fehlen von die Spannung ausgleichenden Einlagerungen neuer Membransubstanz nimmt offenbar deren Dehnung von Teilung zu Teilung zu, bis ihr Widerstand endlich nicht mehr durch den Wachstumsturgor überwunden werden kann. Es wäre im Hinblick auf diese Verhältnisse interessant, die plasmolytischen Grenzwerte derartiger Fäden zu untersuchen. Dieses offenbare Endstadium der Temperaturwirkung zeigt Abb. 4 (Taf. XVI).

Durch dieses Kurzbleiben der Zellen mancher Fäden, die sich offenbar besonders oft und regelmäßig geteilt und dadurch erschöpft haben, wird die Amplitude der Zellänge ganz ungeheuer gesteigert, so daß die längsten sich zu den kürzesten Zellen in derselben Wärmekultur wie 8:1 verhalten. Auf die interessante Erscheinung der Erhöhung der Individualvariation durch hohe Temperatur soll später noch eingegangen werden. Es sei nur noch bemerkt, daß die Zellen desselben Fadens, wenn nicht ganz, so doch über große Strecken dasselbe Stadium morphologischer Beeinflussung zeigen.

Was die Breite der Zellen betrifft, so wird sie gegenüber der KälteKultur in der Wärme meist nur unbedeutend verändert (vermindert).

Hier ist auch der Ort, um kurz auf den Fadenzerfall zurückzukommen, wie er bei verschiedenen Arten in verschieden starker Weise in der Wärme stattfindet. Meist ist nur die Zerbrechlichkeit der Fäden in der Wärme gesteigert, während mehr minder weitgehender autonomer Zerfall in Einzelzellen - besonders bei den Arten mit gefalteter Querwand, die sich dann ausstülpt - vor allem durch geringe Fäulnis des Wassers befördert wird. Bei den Arten mit einfacher Querwand baucht sich dieselbe dem Innendruck entsprechend nur etwas vor.

Blicken wir von hier aus zurück, so müssen wir wohl sagen, daß niemand, dem die Abbildungen Taf. XVI Abb. 1-4 ohne Erklärung vorliegen würden, in ihnen ohne experimentelle Vorkenntnisse die sel be Art, nur unter verschiedenen Temperaturen usw. wiedererkennen würde.

1) Wie ungeheuer diese Zellstreckung namentlich in den ersten 24 Stunden sein kann, zeigt ein keineswegs seltener Fall, in dem mehrere Zellen die Länge von I mm erreichten, während sie in der Kälte bloß 0,3 beträgt. Also Streckung ums Dreifache. 
Daß meine zunächst so auffallenden Beobachtungen nicht vielleicht auf Täuschungen und Vermengung mehrerer Species beruhen, beweist neben dem Umstande, daß das Ausgangsmaterial völlig homogen war und die tägliche Untersuchung alle Utbergänge feststellen ließ, die Tatsache, daß sich in den ersten Tagen manchmal am selben Faden fast alle Utbergänge nebeneinander finden. Das weist aufs neue darauf hin, daß es offenbar das Stattfinden von Teilungen und deren Häufigkeit ist, die als Vorbedingungen des raschen Streckungswachstums in der Wärme diese auffallenden morphologischen Veränderungen als grundlegende Bedingung veranlaßt, wofür später noch Beweise erbracht werden sollen.

Im Zusammenhang mit den Beobachtungen über extreme und rasche Zellstreckung verbunden mit ungenügender oder fehlender Plasma- und Chromatophorenneubildung muß endlich noch auf das Problem des Längenwachstums der Zellmembran eingegangen werden. Bieder mann hat dafür neuerdings eine zusammenfassende Darstellung geliefert ${ }^{1}$ ). Während man für die meisten Pflanzen, besonders Phanerogamen von der Ansicht de Vries' $(1877,79,84)$ und Wortmanns, die das Membranwachstum nur auf einer Art plastischer Dehnung der Membran durch den Turgor als alleinigen Wachstumsfaktor und darauf folgender bloß appositioneller Verdickung zurückführen wollten, zurückgekommen ist, und auf Grund der Arbeiten Strasburgers (1889), Reinhardts und anderer intussuszeptionelles Wachstum gepaart mit geringer plastischer Dehnung annimmt und überhaupt eine innige Wechselwirkung zwischen Plasma und Zellmembran während des Wachstums postuliert, - scheint nach den Untersuchungen Lepeschkins (1907) die ursprüngliche de Vries -Wort mannsche Theorie tatsächlich für Spirogyra in Geltung bleiben zu müssen. Bei dieser Alge soll nämlich gelegentlich des Wachstums tatsächlich der Turgordruck, der eine Art plastischer Dehnung der Zellwand hervorruft, die Hauptrolle spielen und erst sekundär würde dann eine Verdickung der durch Dehnung verdünnten Membran stattfinden, womit eine Entlastung der Zellspannung gegeben ist. Meine Experimente legen nun die Annahme dieser Theorie für Spirogyra unbedingt nahe. Denn in der Wärme herrschen die Abbauprozesse des Plasmas zu osmotisch wirksamen Stoffen so stark vor und der Aufbau jeglicher Stoffe ist so sehr in den Hintergrund getreten, daß sogar die lebende Substanz sèlbst starke Massenreduktion erfährt, so daß an eine Materialaufwendüng für die Neubildung von Zellwandsubstanz absolut nicht $\mathrm{zu}$ denken ist - alle Assimilate und verfügbare Plasmamassen werden veratmet. Es kann demnach das - oft außerordentlich starke und rapide Zellwachstum

1) Handb. d. vergl. Physiologie, herausg. v. H. Winterstein. Bd. III. 1. Teil. 
nach einer Teilung nur durch die passive Dehnung der Membran, durch den osmotischen Druck bedingt sein, keineswegs aber findet autonomes, intussuszeptionelles Membranwachstum primär statt. Daher kommt es auch, daß die Zellmembran in den Wärmekulturen nach einigen Tagen außerordentlich viel dünner und zarter ist als in der Kälte. Es ist so 'in hoher Temperatur gewissermaßen künstlich und experimentell ein reiner Fall von Wachstum lediglich im Gefolge passiver Membrandehnung realisiert, während bei niederer Temperatur offenbar Membranwachstum durch Dehnung gleichzeitig mit appositionellem und intussuszeptionellem Substanzzuwachs erfolgt ${ }^{1}$ ).

Es ist nun noch auf die feineren cy tologischen Veränderungen einzugehen, wobei ich auf die Zeichnungen der Taf. XVIII verweise. Die Chlorophyllbänder (Abb. 44 und 45) verlieren, wie erwähnt, ihren Stärkegehalt und die gezackte Kontur, werden glattrandig und von mohr homogenem Aussehen. Dafür aber tritt eine feine Längsstreifung deutlich hervor, die in Anbetracht des Fehlens alles Assimilate, Granulationen und anderer Einschlüsse gewissermaßen als Eigenstruktur des C.loroplastenstromas anzusehen ist. Diese fibrilläre Struktur wurde auch von Schmitz (88), und zwar dort beobachtet, wo die Chloroplasten bei der Teilung eine Einschnürung erfahren und es scheint also eine gewisse Spannung notwendig zu sein, um diese Struktur sichtbar zu machen, da ja auch in meinen Fällen die gestreckten Bänder sich in geringer longitudinalsr Spannung befinden dürften.

Hier sei auch erwähnt, daß bei dieser Art wie auch überall in der Wärme die Fäden und Fadenwatten eine viel lichter grüne bis gelblichgrüne Färbung annehmen, was einerseits durch die relative Abnahme der Chromatophorenmasse in der Zelle, anderseits durch ein Ausblassen der Farbe, sei es, daß diese nicht oder in nicht genügendem Maße neugebildet wird, während anderseits jedenfalls rascher Verbrauch stattfindet. Farbänderungen bei Temperaturänderung sind von Sirodot und Stahl bei Batrachospermum beobachtet worden. Diese sehr stenotherme, tiefbraune Kaltwasseralge wird schon nach 6 Stunden in .35 bis $36^{\circ} \mathrm{C}$ (nach Stahl) oder nach 24 Stunden in $27^{\circ} \mathrm{C}$ (nach Sirodot) hell rotviolett. Wir haben es wohl hier nicht mit Adaptationsvorgängen im Sinne von Gaidukow, sondern mit gesteigerter Zersetzung und ungenügender Neubildung gewisser Stoffe zu tun, so daß Ausblassen und Metachromasie eintritt.

Die Pyrenoide erleiden oft eine nicht unbedeutende Größenręuk$\operatorname{tion}^{2}$ ), in anderen, selteneren Fällen jedoch erscheinen sie wie gequollen,

1) Über die Beteiligung de Kernes dabei vergl. Wisselingh. 1909.

2) Da dieses Verhalten in hoher Temperatur als typisch anzusehen ist, so sei daran erinnert, daB diese Gebilde offenbar aus Eiweißstoffen bestehen und nach Klebs in Dunkelkulturen eine Schrumpfung und Verkleinerung erfahren, 
jedenfalls sind sie sehr substanzarm, schwach färbbar und heben sich fast nicht von ihrer Umgebung ab (Abb.44, 45). Sie erscheinen auch nach mehrtägiger Wärmekultur von einem lichten Hof umgeben; ob es sich hier um Stärke handelt, habe ich nicht untersucht. Obgleich Teilungen der Pyrenoide gar nicht selten auftreten, so ist die Zahl der Pyrenoide in der Wärme doch pro Zelle geringer als bei niederer Temperatur. In letzterer beträgt sie $30-50$, in ersterer $20-24$ Stück, wobei die Pyrenoide meist dichter aneinander liegen, da ja die Gesamtchromatophorenlänge in der Wärme außerordentlich vermindert ist.

Der Kern zeigt in der Wärme ziemlich bedeutende Größenreduktion (Taf.XVIII, Abb.44 u.45), was im Einklang mit meinen Beobachtungen an Phanerogamen und Tieren steht (Hartmann 35-37), denn allgemein findet Abnahme der relativen Kerngröße bei Temperaturerhöhung statt. Die oft außerordentlich gestreckten Zellen unserer Spirogyra weisen demnach eine ungewöhnliche Verminderung der Kernzellrelation auf. Die Flächengröße des Kernes ist in der Kälte ungefähr $117 \mu^{2}$, in der Wärme $70 \mu^{2}$.

Auch der Nukleolus erweist sich reduziert, seine Größe relativ zum Kern hat sich aber im allgemeinen nicht stark verändert, wohl aber ist er besonders nach längerer Temperatureinwirkung meist außerordentlich stark vakuolisiert und zwar nehmen die Vakuolen eine regelmäßige periphere Lage ein und scheinen oft so dicht gedrängt, daß es so aussieht, als enthielte der Nukleolus in sich noch einen dunklen Körper, der aber nichts weiter ist als der unvakuolisierte, gefärbte mittlere Teil des Nukleolus (Taf. XVIII, Abb.45 u.46). Es ist also zweifellos, daß die Nukleolensubstanz in hoher Temperatur eine starke Auflösung erfährt ${ }^{\mathbf{1}}$ ), ebendasselbe kann man auch an den Nukleolen der höheren Pflanzen und Metazoen konstatieren (vgl. Hartmann .l. c.), wobei allerdings als fundamentaler Unterschied bestehen bleibt, daß jene Nukleolen vorwiegend aus oxyphiler, achromatischer Substanz bestehen, während bei Spirogyra der Nukleolus als Chromatingebilde und durch den Umstand, daB die Chromosomen aus ihm ihre Entstehung nehmen, eine einzigartige Stellung einnimmt ${ }^{2}$ ). Da übrigens auch bei Tieren die chroma-

was mit unseren Beobachtungen bzw. Deutungen der Temperaturexperimente ü̉ereinstimmt.

1) Diese Verkleinerung und Vakuolisation ist deshalb bemerkenswert, weil sich der Nukleolus von Spirogyra bei Verdunk'ung entgezen dem Verhalten der höheren Pilanzen nicht ve:kleinert, aus we'chem Umstande mal mt Recht darauf schließen darf, daß ihm keine Reservestoffunktion zukommt. Meine Ergebnisse bei hoher Temperatur, wo Reduktion stattfindet, stehen damit nicht im Widerspruch, denn dieser Faktor veranlaßt eine Reduktion jeder lebenden Substanz, auch des Protoplasmas.

2) Lit. bei Tröndle, Über die eigenartige Bedeutung des Spiragyra-Kernes, dem die Dignität einer Zelle zukommen soll, vgl. Famitzin. 1912. 
tische Substanz, die dort oft in Gestalt von Pseudonukleolen aufgespeichert ist, in der Wärme eine Reduktion erfährt (Hartmann l.c.), so ist auch diesbezüglich die fundamentale Einheit der Reaktion der Zellbestandteile auf höhere Temperatur im ganzen Organismenreich gewahrt.

Von größtem Interesse sind aber die Veränderungen, die die Kernstruktur in höherer Temperatur durchmacht. In niederer Temperatur (Taf. XVIII, Abb.44) ist der Kern von einer gleichmäßig granulären dichten Chromatinmasse erfüllt und sehr stark färbbar. Nach 2-3 Tagen Aufenthaltes in der Wärme machen sich gröbere Chromatinanhäufungen bemerkbar, die offenbar Zusammenballungen kleinerer Caromatingranula darstellen (Abb. 45) ${ }^{1}$ ). Es läßt sich nun deutlich verfolgen, wie an jenen Stellen, an denen der Kern dem Chromatophor dicht anliegt, er einen lappenartigen, undeutlich begrenzten, breiten Fortsatz entsendet, der dem Bande dicht aufliegt und hier nun gröbere und feinere Chromatinmassen direkt austreten läßt (Abb.45). Es macht den Eindruck, als ob der Kern sich ohne Grenze in die, den Chromatophor überziehende, Plasmaschicht öffnen würde, um seine Granula direkt in den Zellraum übertreten zu lassen. Da auch der Nukleolus sich stark vakuolisiert zeigt, ist es wohl möglich, daß dieser gelöste Stoffe abgibt, die in den Kernraum treten und dort zur Chromatinproduktion verbraucht werden. Jedenfalls muß im Kern eine Zeitlang reichlich neues Chromatin als Ersatz des ausgestoßenen produziert werden, da das ausgestoßene in großer Menge, die die Menge des Kernchromatins fast übertreffen muB, von der Plasmaströmung überallhin in der Zelle herumgeführt wird und besonders der Rand der Chlorophyllbänder und den Primordialschlauch in Gestalt zahlreicher Granula bedeckt. Im Plasma der Zelle werden sie offenbar dann gelöst und verbraucht. Das ausgestoßene Chromatin spielt also in unserem Falle keine besondere formative Rolle, die ihm im Plasma verschiedene Autoren ${ }^{2}$ ) (z. B. Schaxel) gerne bei der Morphogenie von Embryonen z. B. zuweisen möchten, und präsentiert sich auch nicht gerade als wertvoller Erblichkeitsträger, denn es wird einfach als unter den Bedingungen hoher Temperatur im Kern überflüssiger Bestandteil aus demselben wie jedes andere S toff wechselprodukt teilweise entfernt und im Zellraum dann als Näbrmaterial verbraucht, da es allmählich blasser färbbar wird und endlich nicht mehr zu sehen ist. Der Kern ist nach dieser radikalen Chromatinemission, die sich gewissermaßen als Gleichgewichtseinstellung und Anpassung an die veränderten physiologischen Bedingungen in den ersten Tagen abspielt und am 4. Tage meist vollendet ist, sehr klein geworden

1) Diese Veränderungen, die unter diesen Bedingungen übrigens weit verbreitet zu sein scheinen, beobachtet auch Schrammen an Vicia-Wurzeln und ich habe sie an Epidermen von Allium eingehender studiert (vgl. Lit.-Verz. 37).

2) Auf diese Probleme soll später (S. 607) noch eingegangen werden. 
und fast chromatinf rei (Abb.46). Sein Lumen ist nur noch von einem schwach färbbaren Liningerüst erfüllt, dem in extremen Fällen nur mehr ganz vereinzelte Caromatinkörner aufgelagert sind.

Da die meisten charakteristischen Veränderungen schon bei dieser Art eine genauere Besprechung erfahren haben, kann im folgenden d:e Darstellung eine kürzere sein.

b) Spirogyra varians Kützg.

(Taf. XVI, Abb. 5.)

Die Querwände dieser Art sind nicht gefaltet, wodurch sie ohne weiteres von der vorhergehenden, die dasselbe Gewässer bewohnt, abgesehen von der verschiedenen Gestalt des Chlorophyllbandes, unterscheidbar ist. Zellbreite $20 \mu$. Das Chlorophyllband besitzt 5-7, meist 5 Umgänge.

Diese Art wurde ebenfalls am 21. Februar gesammelt und 4 Tage in einer Temperatur von $30^{\circ} \mathrm{C}$ kultiviert.

Während die frühere Art wie wir gesehen haben eine auffallende starke morphologische Temperaturbeeinflußbarkeit besitzt, ist die vorliegende Form in hohem Maße unveränderlich. Nach einer Kulturdauer von 3 Tagen, wonach die andere Alge schon ein total verändertes Aussehen zeigt, ist diese Form, wenn wir von dem Verbrauch der gespeicherten Stärke absehen, in Gestalt und Anordnung der Chlorophyllbänder noch fast normal, so daß sich die zwei Arten, die bei niederer Temperatur immerhin einander bei oberflächlicher Betrachtung ähnlich sehen, nunmehr auf den ersten, flüchtigen Blick total unterscheiden. Infolge der geringen Temperaturbeeinflußbarkeit ist auch die individuelle Variation sehr gering. Am 4. Kulturtage sind nachstehende, gegen die frühere Art minimale, Veränderungen zu finden, die sich fast nur auf das feinere cytologische Verhalten, nicht aber auf die Anordnung der Chlorophyllbänder beziehen. Die Bänder sind zwar dünner, nicht mehr reich granuliert, sondern homogen, aber doch noch mit deutlich gezackten Rändern, selten sind Bilder wio Abb. 6 zu finden, welcher Faden, da er am Ende bereits absterbende Zellen enthielt, jedenfalls nicht als normal zu betrachten ist. Schön ist jedoch gerade hier die offenbar ziemlich weitgehende Verflüssigung der Bänder zu sehen: die vollkommen abgerundeten Kanten, die häufige Ansammlung der Chromatophorenmasse in Kernnähe - die auch bei anderen Arten vorkommt und vor Gerassi mov bei experimentellem Kernüberma $B$ und in Dunkelheit beobachtet wurde - und überhaupt der Gesamteindruck besonders der obersten Zelle in Abb. 6 deuten in dieser Richtung. Besonderes Längenwachstum der Zellen ist nicht zu finden, gleichwohl aber sind die Zellmembranen viel zarter als in der Kälte und wie auch bei anderen Arten mit Hämalaun absolut nicht färbbar, während diese Farbe in der Kälte von 
Längs- und besonders Querwänden deutlich aufgenommen wird. 'Das scheint mir doch auf gewisse chemische Differenzen hinzudeuten, bzw. nahezulegen, daß auch die scheinbar tote Zellwand unter normalen Bedingungen irgendwie lebende Substanz ${ }^{1}$ ) - vielleicht nur geringer Vitalitätsstufe - enthält, die dann infolge des intensiv gesteigerten Stoffwechsels in der Wärme durch überwiegende Dissimilation sich abbaut und die reine Zellulosewand zurückläßt, womit vielleicht auch die Möglichkeit stärkeren, aktiven Membranwachstums verloren gegangen ist.

Die P yrenoide sind in der Wärme reduziert und schwach färbbar. Der Kern erfährt eine starke Größenreduktion, seine Flächengröße ist bei niederer Temperatur $75 \mu^{2}$, in hoher Temperatur nach 4 Tagen bloß $29 \mu^{2}$. Der Durchmesser des Nukleolus ist von $4,5 \mu$ auf $3 \mu$ gesunken.

Von großem Interesse ist es nun, sich die Frage vorzulegen, war u m sich verschiedene Spirogyra-Arten so verschieden stark in ihren morphologischen Charakteren durch hohe Temperatur beeinflussen lassen. Daß physiologische Unterschiede zwischen den einzelnen Arten bestehen, hat Coniere für die Salzresistenz experimentell nachgewiesen; diese ist nämlich obschon bei Spirogyra anderen Gattungen und Familien gegenüber an sich gering, doch bei den Arten mit einem breiten Chlorophyllbande größer als bei denen mit mehreren schmalen. In unserem Falle ist jedenfalls von Wichtigkeit, daß bei vorliegender Art starke Zellstreckungen nach der Teilung im Gegensatz zur vorher besprochenen Art fehlen. Da die Zellstreckung bei ungenügender Substanzneubildung die Hauptursache aller gröberen morphologischen Veränderungen darstellt, so ist das Fehlen der Bandstreckung usw. bei vorliegender Art wohl erklärlich. Es ist nämlich sehr wahrscheinlich, daß diese Art in der Wärme überhaupt die Zellteilungen einstellt. Dadurch aber fehlt dann auch das Streckungswachstum der neugebildeten Zellen in hoher Temperatur und diesen ist so eine der Hauptmöglichkeiten genommen, durch dessen rapide Beschleunigung tiefgreifende morphologische Veränderungen herbeizuführén. Infolge des Fehlens der Teilungen und des darauf folgenden Streckungswachstums erschöpfen sich auch die Zellen nicht so schnell als beider vorher besprochenen Art, da natürlich der ohnehin abnorm gesteigerte Stoff verbrauch in nicht wachsenden Zellen relativ geringer ist als in rapide und oft sich teilenden und wachsenden Zellen.

c) Spirogyra grevilleana (Hass.) Kützg.

(Taf. XVI, Abb. 7--11; Taf. XVIII, Abb. 49, 50.)

Es finden sich Fäden; die fast nur aus Zellen mit einem Chlorophyllbande aufgebaut sind, ebenso solche mit deren zwei; andere Fäden ent-

1) Diese Annahme ist nicht neu, bezüglich der Literatur (bes. Reinhardt) und zusammenfassenden Besprechung verweise ich anf den Artikel Biedermanns im Handb. d. vergl. Physiologie. Bd. III/1. 
halten beide Arten von Zellen mit allen denkkaren Ubergängen ${ }^{1}$ ). Ist nur ein Band vorhanden, so zeigt es zahlreichere Windungen (5-7), als wenn deren zwei gegeben sind $(2-3)$. Die Zellbreite variiert oft ziemlich stark, etwa von 30-35 $\mu$. Die Art wurde am 4. März in einem Tümpel fast in Reinkultur gesammelt und in einer Temperatur von $31^{\circ} \mathrm{C}$ 4 Tage kultiviert, hierauf noch einen Tag bei $40^{\circ} \mathrm{C}$ gehalten.

Die Veränderungen, die sich in hoher Temperatur abspielen, sind, was Bandstruktur usw. betrifft, ganz analog wie bei Spirogyra tenuissima, so daB ich hier ohne einleitende Bemerkungen gleich auf die von Tag zu Tag erfolgende Umbildung eingehen kann. Nach 2 Kulturtagen hat Verlängerung der Zellen stattgefunden, die Zellen mit einem Bande sind meist etwas dünner als die mit zwei Bändern. In den Chromatophoren ist noch ziemlich reichlich Stärke sogar oft noch im Stroma (Stromastärke) vorhanden, dennoch sind die Pyrenoide kleiner und die Bänder schmäler und zarter. Eine merkwürdige Erscheinung findet sich besonders an der Innenseite der Chlorophyllbänder vieler Zellen. Das dort befindliche Protoplasma hat mehr minder zahlreiche, tropfenförmíg sich abkugelnde Teilchen abgeschnürt, die von ziemlich verschiedener, jedoch durchwegs geringer Größe sind und meist eine - die größeren auch wohl mehrere - Vakuolen enthalten. Diese Plasmatropfen sind stärker lichtbrechend und manifestieren sich offenbar als im Absterben begriffene Plasmagebilde. Auf sie soll später noch eingegangen werden.

Nach einer Kulturdauer von 3 . Tagen: Die einigermaßen tiefgreifenden Veränderungen sind auf wenigeFäden und Zellen beschränkt, während die Mehrzahl noch ziemlich normal aussieht. Diese in der Minderheit vorhandenen, veränderten Fäden - ein Faden besteht meist aus Zellen ähnlichen Veränderungsstadiums - haben schon fast gerade und der Längsachse der Zelle parallel gestellte Chromatophoren.

Nach 4 Tagen hat sich die Anzahl der so veränderten Zellen und Fäden stark vermehrt. Der stark gestreckte, schmale, mehr walzenartige Chromatophor liegt meist etwas exzentrisch in der Nähe einer Längswand - wenigstens sein mittlerer Teil, am Ende ist er oft noch etwas gewunden. Die Zellen mit ein oder zwei Chromatophoren unterscheiden sich außer hierin in nichts (Taf. XVI, Abb. 9 u. 10). . Manchmal finden sich auch weniger stark gestreckte Bänder, deren eine Hälfte oft invers

1) Manchmal finden sich auch Zellen mit I1/2 Bändern. Alles deutet darauf hin, daß hier in noch weit regelmäßigerem Maße Verhältnisse vorliegen, wie sie von Kasanowski bei Spirogyra Nawaschini gefunden wurden. Bei dieser Art wächst das Chlorophyllband, sich am Zellende umbiegend, wieder zurück und zwar in demselben Sinne gewunden wie die ursprüngliche Hälfte, bis es an den Ausgangspunkt zurückgekehrt ist, worauf Trennung in zwei selbständige Bänder an der Umbiegungsstelle stattfindet. Bei meinen Exemplaren scheint neben diesem Modus auch Abtrennung eines Stückes und Auswachsen desselben analog einem früher besprochenen Falle vorzukommen. 
gewunden ist, und mithin hat Umkehrung der Richtung stattgefunden. Manche Zellen haben eine extreme Länge erreicht, die bis zum $Z$ weifachen der normalen geht. Im allgemeinen jedoch ist die Zellänge in der Wärme nicht viel bedeutender als in der Kälte, was im Zusammenhang mit der Mehrzahl der anderen Fälle darauf hindeutet, daß die typische Zellänge bei Spirogyra offenbar tiefgreifend erblich fixiert ist, so daß erhöhte Temperatur wohl eine enorme Beschleunigung des Wachstums nach der Teilung bewirkt, aber nur schwer eine wesentliche t'berschreitung des normalen Längenmaximums herrorruft. Daß, wie wir früher sahen, schließlich die erschöpften Zellen nicht mehr die Fähigkeit. bis zur normalen Größe zu wachsen haben, hat damit natürlich nichts zu tun.

Die Chlorophyllbänder mancher Zellen zeigen in selteneren Fällen die Tendenz in Stücke zu zerfallen, welcher Vorgang einerseits durch eine größere Verflüssigung des Bandes, anderseits durch die Spannung, in der es sich offenbar befindet, bedingt ist ${ }^{1}$ ).

Die längs des Chlorophyllbandes zerteilten, oft schon ziemlich ausgeblaßten - d. h. schwach färbbaren - Chromatinkörner deuten auf eine erfolgte, intensive Chromatinemission des Kernes hin, der zu dieser Zeit auch schon recht chromatinarm ist. Der Nukleolus ist fein vakuolisiert.

Am Ende des Cnlorophyllbandes findet man manchmal ein Stück des Bandes abgebrochen (vgl. auch Spir. tenuissima), welches dann selbständig weiter wächst und endlich wohl ein Band normaler Größe, wie bei Spirog. tenuissima liefert. Hingegen wachsen die kleinen Fragmente eines "zerschmolzenen "Bandes - wie man diesen Vorgang anschaulich nennen kann - niemals aus, stellen also wohl Degenerationsprodukte dar (vgl. Taf. XVI, Abb. 12). An den Stellen, wo sich in zweibänderigen Zellen die Bänder berühren, findet oft vollständige, knotenförmige Verschmelzung statt, was in niederer Temperatur niemals beobachtet wird - ein neuer Beweis für die flüssige Natur der Chromatophoren unter den physiologischen Bedingungen höherer Temperatur.

Nach einer Kulturdauer von 4 Tagen bei $31^{\circ} \mathrm{C}$ und einem Tage bei $40^{\circ} \mathrm{C}$ ist der Kern außerordentlich chromatinarm, die Kernmembran aber sehr deutlich und stark färbbar, deutlicher als in der niederen Temperatur. Das deutet auf die Bildung eines stärker verfestigten Oberflächenhäutchens der Kerncolloide hin, das vielleicht aus stark denaturierten oder etwas coagulierten Eiweißkörpern besteht. Dieses Verhalten der Kernmembran ist auch bei anderen Arten zu finden.

Nun noch einiges über die wahrscheinliche Genese der Plasmaklümpchen und ihrer Vakuolen, diese Gebilde wurden einigermaßen

1) Vgl. darüber später; bei Spirogyra nitida, Taf. XVI, Abb. 12. 
ausgebildet nur bei dieser Art.beobachtet. Das Plasma ist offenbar durch die hohe Temperatur teilweise geschädigt, was aber nicht hindert, daß die Zellen tagelang in der hohen Temperatur weiterleben. Die Ent. stehung der Klümpchen ist vielleicht durch Kohäsionsherabsetzung des Plasmas bedingt, sehr wahrscheinlich aber handelt es sich um aktive Abschnürungen, die eine größere Plasmamasse ausstößt, auf Grund irgendwelcher temperaturbedingter, physiologischer Störungen. Von großem Interesse ist die starke Vakuolisation, die offenbar gleichzeitig oder nach erfolgter Abschnürung stattfindet, da die normale Plasmamenge nicht vakuolisiert erscheint. Oft ist eine große Zentralvakuole vorhanden, um die sich peripher rosettenförmig kleinere Vakuolen gruppieren (Taf. XVI, Abb. 11). Die Entstehung der Vakuolen erinnert sehr an die Verhältnisse wie sie Pfeffer an ausgetretenen, absterbenden Plasmaballen von Wurzelhaaren von Hydrocharis beobachtet hat. Wie ich in dem Pfefferschen Falle, und gegen seine eigene Deutung mit Schwarz annehme, handelt es sich bei der Vakuolisation nicht um die Folge übermäßiger Wasseraufnahme und Quellung einer begrenzt quellbaren Colloidphase, sondern um eine Entmischung in heterogenem Systeme. Unser Fall bei Spirogyra scheint mir auch gegen die ursprüngliche Theorie der Vakuolengenese bei Pfeffer zu sprechen. Es finden in den Plasmaklümpchen offenbar starke, vielleicht nekrotische Dissimilationsprozesse statt, durch deren osmotisch aktive Endprodukte Wasser von außen und aus dem Plasma aufgenommen wird, so daß wir also in den osmotisch aktiven Stoffen und ihrem Lösungswasser die eine, in der Hydrocolloidphase des Plasmas unlösliche und deshalb sich in Vakuolenform abscheidende Phase vor uns haben ${ }^{1}$ ). Schließlich wird das ganze Plasma des Klümpchens in osmotisch aktive Stoffe veratmet, wodurch fast nur mehr eine von dünner Haut umgebene Vakuole restiert, die schließlich wohl platzt. Hand in Hand mit dem Plasmaschwund dieser Gebilde und dem Wachstum der Vakuole geht wie zu erwarten - infolge starker Wasseraufnahme eine bedeutende Größenzunahme der ganzen, blasenartigen Gebilde.

Auch bei dieser Art kann man besonders schön dieChromatinemission aus dem Kern in der Wärme beobachten (Taf. XVII, Abb. 50), wobei der Kern den größten Teil seiner intensiv mit Kernfarbstoff (Hämalaun) tingierbaren Masse verliert und nur der dunkle, oft vakuolisierte Nukleolus und ein licht gefärbtes Kerngerüst zurückbleibt. Caromatinemission ist bei Pflanzen mehrfach beobachtet worden, so z. B. produziert der Kern von Antithamnion nach Schiller ${ }^{2}$ ) reichlich Chromatin, das ausgestoßen und offenbar zum Wachstum der Zelle verbraucht wird. Seiner-

1) Man vgl. diesbezüglich meine Arbeit, Lit.-Verz. Nr. 37, und Pantanelli.

2) Weitere Angaben über dieses Thema findet man bei Němec. 1910. 
seits entnimmt nach Schiller der Kern dem Plasma die Stoffe zur Caromatinbereitung, denn bei Verdunklung findet der Prozeß seinen Stillstand. Bei Spirogyra findet offenbar keine solche Stoffaufnahme aus dem Plasma gelegentlich der C'aromatinemission statt, denn gerade bei dem besonders regen Stoffwechsel mit negativer Bilanz, den das Plasma in der Wärme hat, findet ja die Caromatinemission erst ihren Anfang. Es ist also bloß das im Kern in Granula- oder Nukleolusform schon vorhandene Chromatin, wovon die ausgestoßene Substanz stammt. Demnach ist die Chromatinemission von Spirogyra als Ausscheidungsund gewissermaßen als Regulationsproze $B$ anzusehen, denn der Kern ist, wie wir wissen, in der Wärme allgemein auch bei Tieren chromatinärmer. Einen ähnlichen Regulationsprozeß, der sich in Chromatinemission kundgibt, findet man auch bei Protozoen (Hertwig, Popoff): mit gewissen als physiologische Depression bezeichneten Zuständen schwach pathologischen Charakters nimmt der Kern bedeutend an Größe und Caromatinreichtum zu. Wird nun eine solche Depression unter günstigen Außenbedingungen überwunden, so findet oft außerordentlich reichliche Cinromatinabgabe und damit Kernreduktion, gewissermaßen als Gesundungsproze $ß$ statt. Wenn demnach von Cytologen die auch während der Furchung und Organbildung bei Tieren oft stattfindende Chromatinemission in de $\mathrm{m}$ Sinne gedeutet wird, als habe diese ausgestoßene Masse eine besondere, geheimnisvolle, einzigartige, die Plasmadifferenzierungen leitende und lenkende Bedeutung ${ }^{1}$ ) (womit die bekannte Monopolstellung des Kernes bei der Vererbung theoretisch oft zusammenhängt) - so mu B dem ebenso, wie der Ansicht Derschaus, bei dem das Plasma nichts, der Kern aber alles in der Zelle bedeutet, widersprochen werden. Das Chromatin wird in unserem Falle unter den, durch die hohe Temperatur veränderten, physiologischen Gleichgewichtszuständen in der Zelle als überflüssige Substanz ausgeschieden, - dẹnn irgendwelche Bildungsprozesse morphogenetischer Natur die das Chromatin leiten könnte, finden ja überhaupt nicht statt. Wohl aber kann die Chromatinemission als morphologisches Kriterium veränderter und gesteigerter Stoffwechselprozesse angesehen werden (vgl. $R$ ůžiłka).

\section{d) Spirogyra nitida Link.}

(Taf. XVI, Abb. 12; Taf. XVII, Abb. 47, 48.)

Querwände einfach. Vier, selten fünf Chromatophoren mit $1-1^{1} 1 / 2$ Windungen. Zellbreite $70 \mu$. Gesammelt am 28. Februar in ausschließlich diese Form enthaltenden Watten. Wärmekultur 3 Tage bei $30^{\circ} \mathrm{C}$, hierauf noch ein Tag bei $40^{\circ} \mathrm{C}$. Es ist das dieselbe Art, vom selben Fundort, die auch meiner ersten Mitteilung über experimentelle Chromatopho-

1) Vgl. Schaxel, 1915. 
renbeeinflussung zugrunde $\operatorname{lag}^{1}$ ). Ich kann demnach hinsichtlich der Verhältnisse der Chlorophyllbänder, Pyrenoide usw. auf die dortigen Angaben, sowi $A$ Abb. 4-6 der dortigen Tafel verweisen.

Hier seien nur die Verhältnisse am Kern genauer ausgeführt. Was die Beschaffenheit des normalen Kältekernes betrifft, so zeigt ihn Taf. XVIII, Abb. 47. Ein feines, notziges Liningerüst mit aufgelagerten, feinen Chromatinkörnern. Der Nukleolus ist groß und besitzt in der Mehrzahl der Fälle in bestimmter Ansicht einen merkwürdigen Bau. Er hat nämlich zwei blasenartige, lichter gefärbte Partien, die einem dunklen Teile aufsitzen. Als was diese Verhältnisse zu deuten sind, bleibt mir unklar. Bei anderen Spirogyren habe ich dergleichen nie gesehen. In der Wärme schwindet diese Differenzierung und es finden sich nun an dem mehr homogenen Nukleolus mehr minder große Ausstülpungen, die sich oft sehr stark vorwölben und sich abzuschnüren scheinen. Die Kernstruktur ist z.B. nach vier Kulturtagen in der überwiegenden Mehrzahl der Fälle charakteristisch verändert (Taf. XVIII, Abb.48). Der fein retikuläre Bau ist einem Trümmerwerk mehr minder grober und verschieden stark gefärbter Chromatinbrocken gewichen, eine Veränderung, die wir als Vergröberung und Zusammenballung der Chromatinstruktur ziemlich weitverbreitet erkannt haben. Der Nukleolus zeigt sich oft ziemlich stark vakuolisiert. Inwiefern auch er durch direkte Chromatinabgabe am offenbaren Caromatinreichtum des Kernes beteiligt ist, entzieht sich meiner sicheren Kenntnis. Interessant ist es nur, daß auch hier eine morphologisch sichtbare Chromatinemission aus dem Kerne stattfindet und es ist sehr elegant zu sehen, wie die verschieden großen, oft blassen C.rromatinschollen längs der den Kern aufhängenden Plasmafäden nach der übrigen Zelle transportiert werden (Abb. 48). Auf diese Weise entledigt sich der Kern wohl seiner großen Chromatinmenge, denn es finden sich auch Kerne, deren Chromatinreichtum sehr gering ist und sich auf einige Körner und Schollen beschränkt. Bemerkt muß noch werden, daß hier wie in fast allen anderen Wärmekulturen des Genus Spirogyra der Kern nicht mehr im Zentrum des Querschnittes der Zelle gelegen ist, sondern mehr einer Längswand sich genähert hat, was in niederer Temperatur nie der Fall zu sein pflegt.

Hier seien auch noch die Verhältnisse, die man am besten mit dem Ausdrucke "Zerschmelzen " und "Abschmelzen « der Chromatophoren bezeichnet, besprochen. In einigen Tagen dauernden Wärmekulturen dieser Art findet man oft Zellen, deren Chromatophoren in mehrere Stücke zerfallen sind oder zu zerfallen im Begriffe stehen, die entweder gar nicht mehr oder nur durch feine Fäden in Verbindung stehen (Taf. XVI, Abb. 12). Das Bild ist für jedes Teilstück ein ganz ähnliches wie es bei der

1) Vgl. Hartmann, 1917. (Lit.-Verz. Nr. 38.) 
Teilung einer Amöbe auftritt. Als Zentrum jedes Caromatophorenstückes und gleichsam als Bildungskern fungieren ein bis zwei Pyrenoide. Als Ursache dieses Zerfalls, der zwar in lebenden Zellen stattfindet, jedenfalls aber als ans pathologisch grenzende Erscheinung aufzufassen ist, ist neben der mit Temperaturerhöhung zunehmenden Verflüssigung des Ciromatophors, der bei niederer Temperatur eine viel festere Konsistenz zu haben scheint, auch der Schwund der, Zusammenhalt und innere Spınnung ermöglichenden, fibrillären Metastruktur hypothetisch anzunehmen. Es schwindet mit anderen Worten die vitale innere Spannung - eine Art Kontraktilität - des C.romatophors. Solche perlschnurartige Caromatophorenumwandlung hat auch $\mathrm{Küster}$ bei Ceramium beobachtet. Er bemerkt hier mit Recht, daß alle derartigen Umwandlungen, die irgendwie durch die Zelle schädigende Einflüsse hervorgebracht wurden (z. B. Druck, zu hohe Temperatur) wegen ihres pathologischen Ciarakters gar kein Urteil über den normalen Aggregatzustand der betreffenden Gebilde zulassen ${ }^{1}$ ). Aber auch der Umstand, da $\beta$ bei längerer Normalkultur von Ceramium diese Veränderung, sowie Chromatophorenfusion beobachtet wird, welche Veränderungen Küster als physiologische zu Schlüssen über die normale Chromatophorenbeschaffenheit geeignet ansieht, scheint mir dazu nicht die Berechtigung zu erteilen. Denn obgleich es keinem Zweifel unterliegen kann, daß die Masse der Chromatophoren in hohem Grade plastisch ist, ja sich an den Flüssigkeitscharakter bei verschiedenen Bedingungen verschieden stark annähert, so besitzen doch normale, lebende Chromatophoren Eigenschaften, die auf so einfachem physikalischem Wege, d. h. durch Colloidchemische Betrachtungen nicht zu erklären sind. Sie sind als lebende Gebilde kon traktil und befinden sich deshalb in einem eigentümlichen inneren Spannungszustande, der überhaupt auf. einen einfachen Aggregatzustand der Gesamtmasse nicht reduzierbar ist. So ist es überhaupt mit dem lebenden Protoplasma: die Bewegungen einer Amöbe auf Änderungen der Oberflächenspannung zurückzuführen, ist ebenso lächerlich, als dasselbe für das Zusammenrollen eines Igels zu behaupten. Das Plasma ist - und das muß man' heute neuerdings wie zu den 7eiten der Entdeckung der "Monaden " der Biologie, die alles ohne weiteres aus- einfachen Colloidzuständen und Zustandsänderungen herleiten möchte, wiederholen - kein einfaches, mehr minder homogenes Colloid-

1) Besonders grob geht Pono marew mit den Chloroplasten um, indem hier auch verdünnter Alkohol zur Verwendung gelangt, wobei wohl nicht nur die Oberflächenspannung der Chloroplas̀ten verändert wird. Bei $30-33^{\circ} \mathrm{C}$ wird weitgehende Verflüssigung der Chromatophoren von Spirozyra beobachtet, deren Konsistenz normal eine zähflüssige ist. Es ist also die physikalische Beschaffenheit stark von äußeren Faktoren abhängig; wobei normalerweise die Chromatophoren zähflüssiger sind äls das Protoplasma. 
gemenge, sondern es ist lebender, kompliziert org a n isier ter Organismus, dessen Festigkeit und Bewegungsvermögen auf der prinzipiellen Fähigkeit aller lebenden Substanz zur Kontraktilität beruht, die für uns in obigem Sinne eben wenig erklärbar ist als etwa die Reizbarkeit. Eine Amöbe kann sich zweifelsohne auch dann kontrahieren, wenn etwa rein physikalisch betrachtet, ihre Oberflächenspannung zum umgebenden Medium herabgesetzt wurde. Das alles soll zunächst nichts in vitalistischem Sinne bedeuten; sondern bloß eine Mahnung gegen eine gewisse, in ihrer Oberflächlichkeit allerdings durch den Reiz des Neuen entschuldbare Richtung in der modernen Biologie sein. Schmidt z. B. beobachtet, wie aus der zähflüssigen, also ganz amorphen Protoplasmamasse einer zentrifugierten Spirogyra-Zelle ein haardünner Plasmafaden hervorschießt, der sofort mit unbegreiflicher Aktivität begabte, tastende Bewegungen und Schwingungen im Zellraume ausführt. Was für eine Konsistenz mag er haben? Wird man die physikalische Beschaffenheit seines Ursprungs angesichts seiner Tätigkeit auch auf ihn übertragen wollen? Flüssig ist er nicht, auch nicht zähflüssig, denn er führt Bewegungen aus und besitzt in sich offenbar bedeutende Kräfte, die dem physikalischen Abrundungsbestreben entgegenwirken. Sollen wir ihn als fest bezeichnen? Auch das ist angesichts der Tatsachen nicht möglich. Dieser Zustand der Kontraktilität und inneren Festigkeit, die je nach den reizphysiologischen Verhältnissen entsteht und vergeht, kann überhaupt niemals auf diese oder jene physikalische oder colloidchemische Beschaffenheit seiner Gesamtmasse zurückgeführt warden. Es ist ein eigenartiges Spannungsverhältnis der lebenden Masse, als welche abgesehen von diesem Zustande zweifellos als flüssig bzw. zähflüssig aufzufassen ist. Aber die rätselhafte Kontraktilität und innere Aktivität der lebenden Substanz - die macht alle weiteren Schlüsse aus diesen rein physikalischen Befunden illusorisch. Mag man, wenn man Lust hat, immerhin eine komplizierte Metastruktur zur Erklärung heranziehen, jedenfalls ist mit der sich auf normales, lebendes Plasma beziehenden Frage: fest, halbflüssig oder flüssig usw. unter gewissen Umständen nicht viel anzufangen. So meine ich, ist es auch im Falle unserer Chromatophoren. Diese besitzen Kontraktilität und jene eigentümliche innere Festigkeit, die dem an sich flüssigen Stroma die mannigfachen Formen aufzwingt. Unter irgendwelchen diesen Tonus herabsetzenden oder aufhebenden Bedingungen tritt dann die physikalische Natur des Chromatophors, die ihm als leblosen Gebilde zukommt, zutage. Natürlich soll damit nicht bestritten werden, da $B$ auch die rein physikalische Beschaffenheit des Stromas in niederer Temperatur eine festere ist als in hoher. Auch kann man es versuchen, die vitale Spannung auf physikochemischem Wege zu erklären, nur wird man dann ohne die Annahme einer komplizierten Metastruktur kaum auskommen. 
den Einfluß höherer Temperatur auf Morphologie und Cytologie der Algen. 611

An dieser Art habe ich auch untersucht, wie sie sich nach Zurückübertragung aus hoher in niedere Temperatur morphologisch verhält. Die Algen waren 3 Tage in $30^{\circ} \mathrm{C}$, hierauf einen Tag in $40^{\circ} \mathrm{C}$ kultiviert worden und hatten typisch gestreckte und veränderte Chromatophoren erlangt. Sie wurden nun mit demselben Gefäß und dem warmen Wasser in eine Temperatur von $3-5^{\circ} \mathrm{C}$ ans helle Fenster gebracht. Nach 6 Stunden schon hatten einige Fäden sehr viel Stärke um die Pyrenoide angehäuft und deshalb sind an diesen Stellen die Bänder nun stark verbreitert, während sie sonst noch schmal sind. Die Zellen, die sich so schon erholt haben, sind durchwegs sehr kurz, die Chromatophoren sind offenbar stark gewachsen, denn sie weisen zahlreiche enge Windungen auf.

Nach 24 Stunden ist das Bild im wesentlichen dasselbe. Es ist nur der kleinere Teil der Fäden, der sich erholt hat und durch Zellteilung neue Zellen bildet, während der Rest langsam dem Untergange geweiht ist.

Nach 4 Tagen erst kommt es in einigen Fäden zur Ablage von Stromastärke auch entfernt von den Pyrenoiden, womit das Aussehen der Bänder sich schon ganz dem normalen nähert. Infolge der in niederer Temperatur geringen Wachstumsintensität nach der Teilung sind die Zellen sehr kurz, fast nur so lang als breit, mit dicht gewundenen Chlorophyllbändern, die besonders am Pyrenoid starke Stärkeansammlungen zeigen und so perlschnurartig aussehen. Nach 7 Tagen noch sind einige Fäden unverändert mit den Charakteren der Wärmekultur lebend erhalten, ihre C'nromatophoren enthalten absolut keine gespeicherte Stärke, nicht einmal um die Pyrenoide, sie haben glatte Ränder und überhaupt alle Wärmemerkmale. Aber auch die Fäden, die lebhaft Stärke speichern und normal aussehen, haben noch nicht so normal gelappte und gestaltete Chromatophoren wie die. Fäden, die überhaupt niemals der Wärme ausgesetzt waren.

Auffallend ist bei diesen Experimenten besonders der Umstand, daB einige Fäden - die keineswegs in der Minderzahl sind - ohne ihre Wärmecharaktere wesentlich verändert zu haben, offenbar auch ohne sich geteilt zu haben, eine Woche in niederer Temperatur zu leben vermögen. Ihr dauernder Stärkemangel deutet darauf hin, daß sie infolge tiefergreifender Schädigung $\mathrm{zu}$ ausgiebiger Assimilation nicht mehr befähigt sind. Es wäre möglich, daß diese Zellen das Chlorophyll fast vollständig verloren haben und zur Neubildung nicht befähigt sind. Lebendes Material habe ich hier leider nicht untersucht, jedenfalls aber ließen sich schon makroskopisch neben einer Anzahl leuchtend grüner Fäden ganz blasse feststellen. Daß sich diese Fäden trotz mangelnder Assimilation solange lebend erhalten, verdanken sie wohl nur dem durch die niedere Temperatur auBerordentlich reduzierten Stoffwechsel. 
e) Spirogyra weberi Kützg.

Diese mit der vorigen Form ähnliche, aber doch wohl nicht identische Form wurde in einem anderen Gewässer gesammelt. Sie besitzt gefaltete Querwände, meist einen, seltener zwei Chromatophoren, deren Zellen verstreut zwischen jenen liegen. Die Zellbreite beträgt $30 \mu$. Die Kniturdauer in $30^{\circ} \mathrm{C}$ betrug 2 Tage.

Die Alge ist wenig temperaturbeeinflußbar, hingegen verträgt sie die Versuchstemperatur schlecht und nach 2 Tagen sind die meisten Fäden schon abgestorben. Man sieht daraus, wie physiologisch stark verschieden sich sehr ähṇliche Arten derselben Gattung verhalten können. Teilungen finden infolge dieser Temperaturschädigung keine statt, wodurch sich die relativ geringen morphologischen Veränderungen erklären. Die Zellen strecken sich nur etwas, die Bänder werden daher weniger gewunden und verlieren viel Substanz, die Reservestärke und die schön gezackte Randkontur. Diese Veränderungen zeigen gut. Abb. 49, 50 auf Taf. XVIII, von Spir. grevilleana.

Der dünne Plasmawandbelag gibt sich hier besonders schön in der Wärme durch eine feine Reihe kleiner, sehr dunkel und distinkt gefärbter, staubartiger Granula zu erkennen. Es handelt sich hier offenbar teilweise um aus dem Kern ausgesto Bene Chromatinreste, dann aber hauptsächlich um im Plasma bei hoher Temperatur autogene, stark färbbare Körner, die offenbar im Sinne Lepeschkins als Denaturierungs- und Abbauprodukte des Plasmas zu deuten sind und sich, wie dieser Autor experimentell zeigen konnte, in hoher Temperatur sehr ausgedehnt bilden und anhäufen.

Besonders schön ist hier auch eine bei Spirogyra nitida, nicht aber bei anderen untersuchten Arten gefundene Erscheinung zu erkennen. Man findet nämlich in fast allen Zellen an irgend einer Stelle eine oft fast kugelförmige, größere Plasmaansammlung, die oft ein Drittel des Zelldurchmessers an Größe erreicht. Worauf diese Ansammlung eines Teiles des Zellplasmas zurückzuführen ist, bleibt_zweifelhaft, ich glaube, daß es sich um eine Art Reizkontraktion handelt, ähnlich wie wir sie auch an verletzten $Z$ wiebelschalenepidermiszellen an der, der Wundstelle zugewandten Stelle antreffen (vgl. Hartmann 1917, 37). Natürlich sind in unserem Falle nicht traumatische, sondern thermische Ursachen anzunehmen. Der Bau der Plasmaballen ist ausgesprochen fein alveolär, bisweilen findet man kleinere, die eine feinvakuolige struktur zeigen. Das scheint mir die Ansicht $W$ isselinghs zu beStätigen, der für die Genese der Vakuolen im absterbenden Plasma durch Zentrifugieren kernlos gemachter Spirogyra-Zellen Entstehung aus dem normalen Plasmawabenwerk annimmt und auch beobachten konnte. Damit, sowie mit meinen früher mitgeteilten Beobachtungen 
über das Auftreten von Vakuolen in beliebigen abgeschnürten Plasmaklümpchen, scheint mir die Ansicht von de Vries und Went, die in den Vakuolen ein spezifisches, sich ausschließlich durch Teilung vermehrendes Zellorgan erblicken, deren Wand ein eigentümliches Gebilde, den Chtonoplast bilden soll, widerlegt, wie ja auch die physikalische Chemie der Zelle seit einiger Zeit die Semipermeabilität als Grundeigenschaft jeder, auch neugebildeten Plasmaoberfläche anzusehen sich gewöhnt hat.

\section{Zygnema affine Kützg.}

(Taf. XVI, Abb. 13, 14.)

Die sternförmigen Chromatophoren sind auf Reize sehr empfindlich, es findet in diesem Fall mehr minder weitgehende Kontraktion bis zur Kugelform statt, wobei die Plasmafäden zunächst noch ausgespannt bleiben und sich erst ganz zuletzt ebenfalls einziehen. Eine teilwe:se Kontraktion, wie sie durch das Schütteln beim Transport bedingt ist, zeigt Abb. 13, eben dasselbe konnte auch Klebs (47) bei Verdunklung beobachten. Unter dem Einflu $B$ von Kocksalzlösungen konnte Rich ter dasselbe feststellen, die Zellenmembran wird unter diesen Umständen dicker und bekommt einen ausgesprochen schichtigen Bau. Interessant ist es, daß bei $1-6 \%$ Lösungen der Zellinhalt mit der Zeit vollständjg schwindet, es verzehrt sich also die lekende Substanz infolge Unvermögens zur Neubildung gewissermaßen langsam selbst auf. Da $B$ übrigens Neutralsalze, speziell $\mathrm{NaCl}$ vielfach einen die Atmung und Dissimilation stark erhöhenden Einflu $\beta$ haben, ist aus der tierischen Physiologie bekannt').

Gegen hohe Temperatur war diese Alge in meinen Versuchen außerordentlich empfindlich: ein Tag Aufenthalt in $31^{\circ} \mathrm{C}$. genügt, um alle unter totaler Abkugelung von Plasmafasern und Chromatophoren atzutöten. In $28^{\circ} \mathrm{C}$ gelingt es, sie 1-2 Tage am Leben zu erhalten. Hr̈r findet zunächst Kontraktion der Chromatophorenausläufer statt, an die sich die der Plasmafasern anschließt. Der Sternchromatophor und seine Plasmafasern stellt sich in der Kälte als gleichmäßig strahlenförmiges, sich verzweigendes System dar, das sich an die Zellwände anheftet. Die äußersten Enden beginnen sich zuerst zu kontrahieren, wobei sie am Ende kugel- bis keulenförmige Anschwellungen zeigen. Sie bieten mit einem Wort ganz dasselbe Bild, wie es sich bei der Reizkontraktion der Filo- und Rhizopodien der Rhizopoda darbietet2), oft sieht so der ganze Chromatophor wie die mittelalterliche Waffe "Morgen-

1) Vgl. Oppenheimers Handbuch der Biochemie des Menschen und der Tiere, die Artikel über Salzwirkung, Atmung usw. (Verschiedene Bände.) Jena $1908 \mathrm{ff}$.

2) Vgl. M. Verworn, Allgem. Physiologie. Jena 1909. 
stern " aus. Dieses Ubergangsstadium, das endlich zu totaler Ansammlung des ganzen Zellinhaltes mit Ausnahme des Plasmawandbelages in Gestalt zweierKugeln führt, zeigt in verschiedenem Grade der Ausbildung Taf. XVI, Abb. 13. Die knopfförmigen Verdickungen und Abrundungen der Strahlen am Ende sind oft gut erkennbar. Hand in Hand mit dieser Temperaturwirkung geht ein starker Schwund von Chromatophoren- und Plasmasubstanz wie ein Vergleich der Größe auf Abb. 12 und 13 dartut. In der Wärme findet auch oft eine ziemlich bedeutende Zellstreckung, offenbar ohne daß eine Teilung erfolgt wäre, statt (Abb. 13, linker Faden), die mit einem auffallenden Zarter- und Dünnerwerden der Zellmembran verbunden ist. Offenbar findet rein passives, osmotisch bedingtes Streckungswachstum unter Membrandehnung statt. Die Gallerthülle ist in der hohen Temperatur nicht nachweisbar, offenbar wurde sie aufgelöst ohne ersetzt zu werden.

Der Kern nimmt an Größe und Färbbarkeit seiner Granula ziemlich bedeutend ab und enthält auch weniger Einschlüsse, der Nukleolus ist lichter geworden und vakuolisiert.

\section{Mougeotia scalaris Hass.}

(Taf. XVI, Abb. 15, 16; Taf. XVIII, Abb. 51, 52.)

Das Material wurde in einem Tümpel am 21. Februar gesammelt und 4 Tage bei $30^{\circ} \mathrm{C}$ kultiviert. Diese Alge verträgt die hohe Temperatur ausgezeichnet, Abstérbeerscheinungen gehören innerhalb dieser Zeit zu den größten Seltenheiten.

Der plattenförmige Chromatophor dieser Alge ist außerordentlich auf Reize empfindlich und antwortet mit Kontraktion, so auf Licht und Dunkelheit, hohe und niedere Temperatur, wenn sie unvermittelt geboten werden (vgl.Senn). Interessant ist, daß nicht bloß der Wechsel der äußeren Bedingungen die Kontraktion hervorruft, sondern daß nach Senn bei Temperaturen um $4^{\circ} \mathrm{C}$ auch im Freien die Platten niemals ausgebreitet sind, erst von $9^{\circ} \mathrm{C}$ aufwärts besitzen sie die typische Gestalt. In meinen Experimenten wurden natürlich nur Zellen mit ausgebreiteten Chromatophoren, die bei sorgfältiger Behandlung sowohl bei hoher als niederer Temperatur dominieren, verwendet. Obgleich wahrscheinlich in $30^{\circ} \mathrm{C}$ zunächst eine Kontraktion stattfindet, so geht sie doch jedenfalls schon im Verlaufe des ersten Tages zurück und tritt dann nie wieder auf - die Anpassung an die hohe Temperatur ist in reizphysiologischem Sinne vollzogen.

Die Veränderungen, die in der Wärme vor sich gehen, sind auf den ersten. Blick nicht so bedeutend und beziehen sich vorzüglich auf die feinere Struktur. Wir legen den folgenden Besprechungen Exemplare zugrunde, die 4 Tage bei $30^{\circ} \mathrm{C}$ gezüchtet worden waren. Meist findet eine deutliche, oft sogar starke Zellverlängerung statt. Neben Zellen 
mit bis zum Vierfachen der normalen Länge findet man aber auch gehemmte, die nur die Hälftë des Normalmaßes messen.

Durch die Teilungen und den starken Stoffwechselbedarf sind die Chromatophoren sehr dünn und zart und entbehren aller gröberen Einschlüsse und der Stärke. Die Zahl der Pyrenoide, die offenbar in nicht genügendem Maße neugebildet werden, beträgt drei bis vier, gegenüber etwa sechs in der niederen Temperatur.

Besonders in den ersten Tagen findet die Zellstreckung so rasch statt, daß der Chromatophor nicht bloß in der Substanzzunahme, sondern auch in der Flächenvergrößerung hinter der Zelle zurückbleibt und dann oft nur an den Zellecken mit je einem zipfelförmigen Teil fixiert ist, so daß er gewissermaßen wie ein an den vier Ecken gespanntes Tuch in der Zelle aufgehängt und auseinandergezogen ist. Bekanntlich hat Kolkwitz für Spirogyra die Ansicht ausgesprochen, daß hier die Bänder in der Zelle sich in Spannungszustand befinden, was allerdings Oltmanns bezweifelt. Sprechen nun schon bei Spirogyra meine Experimente mit hoher Temperatur, die eine Zell- und Bandstreckung hervorruft, für einen wenigstens während des Streckungsprozesses stattfinderden longitudiinalen Zug auf die Chromatophoren, so ist bei Mougeotia diese Spannung unzweifelhaft. Normalerweise mag sie ja gering sein, aber die Platte ist frei im Zellumen aufgehängt und daher muß eine rasche Zellstreckung, der das Chromatophorenwachstum nicht zu folgen vermag, zu beträchtlichen Dehnungs- und Spannungszuständen führen, die sich besonders in den ersten Tagen bemerkbar machen, da hier jedenfalls am reichlichsten osmotisch bedingtes Streckungswachstum stattfindet.

Ein Zerfall der Fäden in Einzelzellen konnte nicht beobachtet werden, dazu ist wohl neben hoher Temperatur noch geringer Fäulniszustand des Wassers erforderlich. Die Pyrenoide, in der Kälte mit einem Durchmesser von durchschnittlich $4,8 \mu$, haben in hoher Temperatur nur einen solchen von $4 \mu$, außerdem sind sie sehr substanzarm und daher schwach färbbar.

Der Kern zeigt eine mittlere Verkleinerung seines Durchmessers von $13 \mu$ auf $11 \mu$, der Nukleolus von 6 auf $5 \mu$. Oftmals sind jedoch beide Gebilde auffallend angeschwollen, wie ein Vergleich der Abb. 51 und 52 zeigt. Es findet nämlich Abbau des in der Kälte reichlich in Granulaform vorhandenen Chromatins statt, das im Wärmekern sich auf wenige Granula, die das nunmehr sehr deutlich hervortretende achromatische Kerngerüst bedecken, beschränkt. Durch diesen Chromatinabbau werden offenbar osmotisch wirksame Stoffe gebildet, die durch Wasseraufnahme in den Kern dessen Volumen vergrößern ${ }^{1}$ ). Ähnlich

1) Ganz Ähnliches findet man auch beim Meristem der Phanerogamenwurzel 
verhält sich der Nukleolus, der außerordentliche Vakuolisation zeigt (Abb. 52). Auf dieser Abbildung sind fast nichts mehr als drei gegeneinander abgeplattete Vakuolen da. DaB Stoffabgabe vom Nukleolus in Gestalt kleiner sich färbender Granula stattfindet, erscheint nicht unwabrscheinlich, ebenso daß der Kern einen Teil des Chromatins in Granulaform an das Plasma abgibt. Gleichwohl ist der Mougeotia-Kern in der Wärme ein Beispiel eines Kernes, der nicht durch Abgabe fester färbbarer Bestandteile in dem Maße wie bei Spirogyra, sondern vor allem durch den Abbau in lösliche, osmotisch wirksame Stoffe seinen Chromatinbestand vermindert, was oft so stark geschieht, daß viele Kerne sich überhaupt nicht mehr mit Kernfarbstoffen nennenswert färben.

\section{Desmidium Swartzii Ag. \\ (Taf. XVI, Abb. 17, 18.)}

In der Kultur bei $30-31^{\circ} \mathrm{C}$ bedecken die zwei Chromatophoren, die bei niederer Temperatur in der Zellenmitte zusammenstoßen und die Zelle auch sonst vollständig erfüllen, nur mehr als zwei wandständige, auch nicht mehr die Zellänge ganz erfüllende, Platten die Querwände. Da diese Erscheinung auch nach 4 Tagen in der Wärme noch zu beobachten ist, während sie nach einem Tage erst in Entstehung sich befindet, so handelt es sich offenbar nicht so sehr um Kontraktion als" Reizwirkung, als um eine bedeutende Massenreduktion der Chromatophorensubstanz, die $c^{\prime}$ 'n eine bekannte Begleiterscheinung der negativen Stoffwechselbilanz in der Wäıme ist. Es liegt uns also hier ein Fall vor, wo unabhängig von Zellbildung und Zellstreckung die Cbromatophoren durch direkten Verbrauch ihrer Substanz eine bedeutende Massenreduktion erfahren. Ein Vergleich der feineren Zellinhaltsverhältnisse ist undurchführbar, da die Chromatophoren besonders in der Kälte den Einblick ins Innere versperren.

\section{Protococcus olivaceus Rabenh.}

(Taf. XVIII, Abk. 53, 54.)

Für die Sicherheit der Bestimmung kann ich mich hier nicht verbürgen, da die Bestimmungsschwierigkeiten in dieser Algengruppe bekannt sind. Für die Untersuchung wurden nur Einzelzellen verwendet, nicht solche, deren Inhalt im Begriffe stand, in mehrere Tochterzellen zu zerfallen. Die normalen Zellen in der Kälte zeigen einen becherförmigen Chromatophor, der zu zwei Drittel die große Zentralvakuole der Zelle umspannt (Abb. 53). Der Kern, der sich sehr dunkel färbt

in den höchsten Temperaturen, wo eine gegenüber etwas niederen Temperaturen sekundäre Kernvergrößerung stattfindet. In meiner diesbezüglichen Arbeit findet man auch eine darauf Bazug nehmende genauere Analyse cytologischer Gleichgewichte. 
und in dem deshalb nur mit Mühe eine dunklere Zentralpartie als Nukleolus erkennbar ist, liegt dem Chromatophor an. Außerdem findet sich ein großes Pyrenoid mit Stärkescheide.

In den ersten zwei Kulturtagen in hoher Temperatur $\left(31^{\circ} \mathrm{C}\right)$ bilden sich die Verhältnisse heraus, die wir dann am dritten Tage beobachten. Nach 4 Tagen haben sich die Zellen schon mit einer sehr derben Hülle umgeben und sind offenbar in eine Art Ruhestadium eingetreten, weshalb sie im folgenden nur die Verhältnisse nach drei Kulturtagen berücksichtigen: Plasma und Chromatophor, die in niederer Temperatur scharf voneinander gesondert sind (Abb. 53), sind nicht mehr als getrennt erkennbar. Die Zelle ist meist von einer mehr minder stark vakuolisierten, schaumartigen plasmatischen Masse erfüllt (Abb. 54), die offenbar Plasma und Chromatophorenstroma gemeinsam darstellt. Das Aussehen dieses Schaumwerkes, das sich ziemlich stark, stärker als das Kälteplasma, aber schwächer als der Kältechromatophor färbt, ist ein mehr homogenes. Ein Pyrenoid ist oft nicht sichtbar, vielleicht aber nur durch die Vakuolisation des Zellinhaltes unsichtbar gemacht. Die starke Vakuolisation, die natürlich auf starkem Flüssigkeitsreichtum beruht, bewirkt auch den im allgemeinen größeren Durchmesser der Einzelzellen.

Der Kern hat meist außerordentliche Reduktion erfahren und ist oft nicht einmal mehr als distinkter, einheitlicher Körper nachweisbar, sondern als eine Chromatinmenge, die zwischen einige benachbarte Wabenwände in dünner Schicht verteilt ist. Manchmal resistiert er auch noch als dunkle, kollabierte, wandständige Masse in der Zelle. Jedenfalls aber ist ein großer Teil seines Chromatins in Brockenform in den Wabenwänden durch die ganze Zelle verstreut.

In den Zellen, die sich nach viertägiger Kultur mit derben Membranen umgeben haben, ist die Vakuolisation und der Schwund des Zellinhaltes noch bedeutender, auch ist die Färbbarkeit mit Hämalaun demgemäß stark herabgesetzt.

Uberblicken wir also das Wesentliche dieser temperaturbedingten Umwandlung, so finden wir es in einer enormen Vakuolisation und Substanzschwund der nicht mehr trennbaren Chromatophoren- und Plasmamasse. Obgleich diese Veränderungen zweifelsohne ans Pathologische grenzen, so findet doch Schwärmsporenbildung oft noch statt. Daß diese Vakuolisation auf vermehrter Dissimilation und Produktion osmotisch wirksamer Zerfallsprodukte beruht, womit ein neues Beispiel für das Uberwiegen der dissimilatorischen Stoffwechselphase als. Abnahme der Stoffwechselökonomie gegeben ist, erscheint klar. Während jedoch z. B. bei Spirogyra die osmotisch aktiven Stoffe ins Zellinnere, in die Zentralvakuole abgegeben werden, findet das hier nicht statt, im Gegenteil, es findet innere Vakuolisation der plasmatischen und 
chromatophoren Substanz so weitgehend statt, daß die Zentralvakuole der Zelle verdrängt wird. Es verhält sich hier der Zellinhalt in seiner inneren Vakuolisation ähnlich wie der Nukleolus, z. B. bei Spirogyra und Mougeotia, denn z. B. auch bei Phanerogamenwurzein ${ }^{1}$ ) wird in hoher Temperatur zwar die Zelle stark vakuolisiert, es bilden sich aber nur ein bis zwei, seltener mehr große Hauptvakuolen heraus, niemals jedoch eine Schaumstruktur ${ }^{2}$ ) des Plasmas. Es scheint, daß in unserem Falle vielleicht durch eine Veränderung der Permeabilität des Zellinhaltes dieser seine in großer Menge gebildeten Zerfallsprodukte nicht schnell genug der Zentralvakuole zuführen kann, so daß diese durch Wasserattraktion die totale Vakuolisation aller lebenden Substanz bewirken. Zu erwähnen bleibt noch, daß Hand in Hand damit ein Abbau des grünen Farbstoffes der Algen erfolgt, die schließlich séhr weitgehend ausblassen. Es ist offenbar eine vollständige Reduktion und Aufzehrung der Chromatophoren ${ }^{3}$ ) im Gange, wobei am Ende dieser Desintegration von Plasma und Chromatophor nur mehr eine homogene Schaummasse resistiert; dennoch aber leben die Zellen und treten durch derbe Hüllenbildungen in eine Art Ruhestadium ein.

\section{Vaucheria sessilis (Vauch.) D.C.}

Von dieser Alge werden zwei Kulturen angelegt. Das eine Material wurde dem Tümpel am 19. Februar entnommen und 2 Tage in $30^{\circ} \mathrm{C}$ kultiviert, das zweitemal wurde demselben Gewässer Material im Juli bei einer Wassertemperatur von etwa $20^{\circ} \mathrm{C}$ entnommen und dasselbe bei $36^{\circ} \mathrm{C}$ mehrere Tage gehalten. Bei der Kultur dieser Alge handelte es sich mir besonders um den Einfluß der Temperatur auf die Größe der Chromatophoren. Die Gestalt derselben ist in der Kälte meist eine längliche, in der Wärme oft mehr rundlich aber auch oft länglich. Sie sind durch Plasmafäden untereinander verbunden. Das Öl, das, wie dürch Borodin bekannt, als Assimilationsprodukt bei dieser Gattung statt Stärke erscheint, ist auch in der Wärme oft noch in Gestalt kleinster Tröpfchen in den Chloroplasten enthalten. Die Struktur der Chloroplasten ist an fixierten und gefärbten Präparaten in der Kälte eine deutlich granuläre, in der Wärme mehr homogene und auch stärker lichtbrechende, was darauf hinzudeuten scheint, daß die Verkleinerung der Gebilde, die, wie wir gleich sehen werden, in der Wärme stattfindet, ähnlich wie unter gewissen Umständen bei Phanerogamenchlorophyllkörnern zum Teil auf Wasserabgabe beruht.

1) Vgl. Hartmann (37), wo auch das Problem der Zellvakuolisation und Vakuolengenese eingehend erörtert wird.

2) Besprechung der Genese der Vakuolen aus der normalen Alveolärstruktur der lebenden Substanz bei Wisselingh (Bot. Zentralbl.).

3) Weitgehender Chromatophorenschwund wird bei Algen auch in organischen Nährlösungen beobachtet, vgl. Matrouchot u. Molliard. 
den Einfluß böberer Temperatur auf Morphologie und Cytologie der Algen. 619

In der ersten Experimentalserie sind die Dimensionen der Chloroplasten in der Kälte $4-6 \mu$ in der Länge, 2,5-3 $\mu$ in der Breite, in der Wärme etwa $3,4 \mu$ im Durchmesser. In der zweiten Experimentalkultur beträgt der Durchmesser in der Kälte 3,5 $\mu$, in der Wärme $2,9 \mu$. Die entsprechenden Maße für die Kerngröße sind 2,5 bzw. 2,3 $\mu$ für die Kältekultur, 1,8 $\mu$ für die Wärmekultur, für den Nukleolus 1,1 bzw. 1,3 in der Kälte, 1,1 bzw. 1,0 in der Wärme.

Uber eine Veränderung der Kernstruktur, über deren normales Verhalten und bei der Teilung man bei Kursanoff nachlesen möge, ist in Anbetracht der Kleinheit der Objekte nur zu bemerken, da $B$ der in der Kälte in der Einzahl vorhandene, kompakte Nukleolus, in der Wärme in einen Haufen einiger nahe beieinander liegender Körner sich umwandelt, was offenbar auf eine beginnende Substanzreduktion hindeutet. Die Anzahl der Kerne auf gleichgroßem Gebiete scheint durch die hohe Temperatur unverändert zu bleiben.

\section{Oedogonium spec.}

(Taf. XVI, Abb. 19-21.)

Das Material wurde am 21. Februar gesammelt und mehrere Tage bei $30^{\circ} \mathrm{C}$ kultiviert. In einigen Fäden früher, in anderen später, finden Veränderungen statt, die sich als allgemeine Erschöpfung und Substanzschwund infolge enorm gesteigerten Stoffverbrauches auffassen lassen. Die Zellen, die in niederer Temperatur mit Stärkekörnern derart vollgestopft sind, da $B$ von Chromatophoren und anderem Zellinhalt überhaupt nichts zu sehen ist und nur der Kern, undeutlich durchschimmert (Abb. 19), verlieren in der Wärme zunächst einen großen Teil ihrer Stärke, so daß nunmehr die netzartige Anordnung des Chromatophors gut erkennbar ist (Abb. 20). Der Kern hat starke Größenreduktion erfahren. Auf diesem Stadium sehen die Algen noch ganz normal und typisch aus. Aber der Substanzverbrauch geht weiter, bis auch der letzte Rest von Stärke verbrannt ist und auch die Chromatophorensubstanz sowie das Plasma hochgradig reduziert erscheint. Die Chromatophoren besitzen fast keine Anastomosen untereinander mehr, sondern stellen einfache, längsverlaufende, dünne, schwach färbbare Bänder aus hyalinem Plasma dar (Abb. 21). Die Selbstreduktion der lebenden Substanz geht jedoch noch weiter, bis neben dem Kern, der aufs äußerste reduziert ist und chromatische Degeneration zeigt, überhaupt so gut wie kein Plasma mehr vorhanden ist, also die Zelle fast vollständig leer erscheint.

Oedogonium ist demnach ein typisches und wundervolles Beispiel dafür, wie gesteigerte und ungedeckte Dissimilation nach Verzehrung der Reservestoffe auch die lebende, stoffwechselnde Substanz selbst in hohem Maße angreift und so zu deren fast vollständigem Selbstver- 
brauche führt. Interessant ist es nun, daß diese Selbstverbrennung der lebenden Substanz bis zu deren vollständigem Schwund in einer le ben den Zelle, ohne daB früher Absterben erfolgte, stattfindet, solange auch nur eine kleine Plasmamenge noch vorhanden ist ${ }^{1}$ ). Diesen ganzen Schwund des lebenden Inhaltes der nichts Pathologisches an sich trägt, sondern nur der Ausdruck extrem verschobenen Stoffwechselgleich子ewichts ist, in seinen einzelnen Stadien bis zuletzt zu verfolgen, gewährt ein hohes Interesse, leider muß ich es mir versagen, auf Einzelheiten genauer einzugehen.

Hier soll nur noch bemerkt werden, daß solange in der Zelle Plasma noch ziemlich reichlich vorhanden ist, sich von diesem oft mehr minder große Massen abschnüren, die dann vielfach stark sich vakuolisieren. Die Genese dieses sich oft aneinander abplattenden Vakuolenschaumes ist im Sinne Wisselinghs zu deuten, über deren Ursache hier schion des öfteren gesprochen wurde.

\section{Microspora stagnorum (Kg.) Lagerh.} (Taf. XVI, Abb. 22, 23; Taf. XVIII, Abb. 55, 56.)

Die auf feuchten Steinen am 26. Februar gesammelten Algen wurden 2 Tage in $30^{\circ} \mathrm{C}$ kultiviert. Die Chromatophoren, die in der Kälte mebr dicke und massige, untereinander anastomosierende Bänder bilden, so da $B$ in der Aufsicht meist das Bild einer gefensterten Platte entsteht (Abb. 55, Taf. XVIII), haben sich in der Wärme mehr minder stark reduziert, sie bedecken nur mehr einen kleinen Teil der Zellwände und lassen große Stücken frei. Meist ist von ganzem Cinromatophorensystem nur mehr eine wandständige Leiste übrig und von einer Mehrheit anastomosierender Chromatophoren ist nichts mehr zu sehen (Abb. 23, Taf. XVI). Auf noch weiter vorgeschrittenen Stadien ist überhaupt kein Chromatophor mehr unterscheidbar (Abb. 56, Taf. XVIII), die Zelle ist nur von einem spongiösen Plasmanetzwerk, das stellenweise kompakter ist, erfüllt. Am Rande finden sich bisweilen spärliche Reste, die vielleicht von Chromatophoren abstammen. Jedenfalls haben wir auch bei dieser Alge den Fall einer vollständigen Desintegration und Einschmelzung der Chromatophoren vor uns. Die in der Wärme zunächst noch sichtbaren Chromatophoren sind sehr hyalin, dünn und offenbar sehr locker gebaut, bisweilen direkt spongiös oder vakuolisiert, während die Kältechromatophoren dicht, kompakt und stark färbbar erscheinen, wie uns ein Vergleich der Photographien Abb. 22 und 23 zeigt.

Der Kern zeigt in der Wärme Chromatinschwund und schwache Färbbarkeit. An den Plasmasträngen in der Zelle finden sich oft dunkle Granula, die offenbar ausgestoßenes Chromatin darstellen.

1) Die Pyrenoide erfahren in der Wärme außerordentliche Substanz- und Größenreduktion, auch schon, wenn noch Stärke in der Zelle vorhanden ist. 
den Einfluß höherer Temperatur suf Morphologie und Cytologie der Algen. 621

Die Färbbarkeit der Zellmembran, sowie überhaupt des ganzen Zellinhaltes, hat bedeutend abgenommen, erstere ist in Hämalaun überhaupt ungefärbt.

9. Ulothrix zonata Kützg.

(Taf. XVII, Abb. 24, 25.)

Das Material entstammt einem Mühlgang und wurde am 20. März gesammelt und in $31^{\circ} \mathrm{C}$ kultiviert.

Diese Gattung ist sehr wenig widerstandsfähig gegen hohe Temperatur, was zum Teil auch damit zusammenhängen mag, daß sie fließendes Wasser, also reichliche Durchlüftung, gewohnt ist. Nach 3 Tagen Warmkultur waren alle Fäden abgestorben, nach 2 Tagen bereits die meisten, so daß sich meine Angaben auf eintägige Kulturdauer beziehen mïssen. In der Kälte sind die Cnromatophoren Ringplatten (Abb. 24), die etwa $2 / 3$ der freien Zellwand bedecken, das übrigbleibende Stück ist meist von Pyrenoid ausgefüllt. Die Chromatophoren sind dicke, sich stark färbende, feine fibrilläre Struktur zeigende Platten.

In der Wärme geht die regelmäBige Gestalt der Cnromatophoren ganz verloren. Was man jetzt als Zellinhalt erkennt, ist nur eine gleichmäßige granulierte plasmatische Masse, die offenbar zum größten Teil aus der degenerierten Chromatophorensubstanz besteht (Abb. 25). Einzelne Zellen sind besonders stark degeneriert und infolge ihres sinkenden Turgordruckes durch die Nachbarzellen stark zusammengedrückt (Abb. 25).

Der Kern hat eine bedeutende Größenreduktion erfahren. Obwohl uns auch diese Alge unzweifelhaften Caromatophorenschwund demonstriert, so ist derselbe doch wegen seines unzweifelhaft pathologischen Charakters aus der Reihe der physiologischen Umbildungsprozesse, die wir früher immer vor uns hatten, zu streichen und hier nur der Vollständigkeit halber angeführt worden.

10. Stigeoclonium spec.

(Taf. XVII, Abb. 26, 27; Taf. XVIII, Abb. 57, 58.)

Diese Alge wurde in Form von Filzen, die abgefallene Blätter bedeckten, in einem Tümpel am 4. März erbeutet und 2 Tage bei $31^{\circ} \mathrm{C}$ kultiviert. Nach 3 Tagen zeigen sich Absterbeerscheinungen.

Neben den uns bekannten Erscheinungen des Schwundes der Assimilate in der hohen Temperatur, der Reduktion des Plasmas, das sich übrigens wegen seines Chromatingehaltes in der Wärme dunkler färbt, möchte ich hier vor allem die Aufmerksamkeit auf das Verhalten des Kernes lenken. In der niederen Temperatur (Taf. XVUI, Abb. 57) zeigen besonders die Kerne der mehr basal gelegenen Teile des Fadens eine ungemein reichliche Verzweigung und komplizierte Gestalt. Feinste, 
oft kaum sichtbare Fortsätze zwängen sich, oftmals sich teilend, zwischen die Pyrenoide, Stärkekörner und Plasmagranula hinein, so da $B$ ihre Verfolgung oft überhaupt nicht oder nur schwer möglich ist (Abb. 57). Auch auf der Photographie Abb. 26 sind die gröberen dieser Fortsätze als dunkle, das Plasma durchziehende Stellen besonders im oberen Teile der Abbildung gut erkennbar. Der Kern besitzt einen Nukleolus und eine große Menge feiner Chromatinkörner, die, besonders peripher lagernd, auf dem Wege der Kernfortsätze bis weit in die Zellmasse hinein transportiert werden. Daß der Kern in inniger Beziehung zum Plasma stehen kann, ist durch die Untersuchungen von Derschau über Kernbrücken, durch die hindurch das Linin und Chromatin des Kernes auf die Plasmawabenwände hinausgelangt, nachgewiesen. Es. ist auch in unserem Falle so etwas nicht unwahrscheinlich, nur möchte ich betonen, da $B$ wenigstens die gröberen Fortsätze einfach Ausstülpungen des.Kernes sind, der eben eine rhizopodenartige Gestalt annimmt, nicht aber ohne we:teres als Ausfallspforte (Kernbrücke) der Kernsubstanzen aufgefa Bt werden dürfen.

In hoher Temperatur ist der Kern niemals so gestaltet, sondern abgerundet und ohne jegliche Fortsatzbildungen (Taf. XVII, Abb. 27, Taf. XVIII, Abb. 58). Seine Chromatinstruktur hat sich, wie wir das als typisch für dieWärmewirkung schon oft bezeichneten, sehr stark vergröbert, indem besonders wandständig große Chromatinmassen offenbar als Verschmelzungsprodukt kleinerer Granula auftreten. Es scheint nicht ausgeschlossen, daß diese Ansammlung des Chromatins zu größeren Massen durch zunehmende Verflüssigung bedingt bzw. ermöglicht wird. Die Chromatinmassen wölben vielfach die Kernmembran etwas nach außen vor und wenn sie auch nicht als so große Massen ins Plasma über treten, so findet doch offenbar Substanzabgabe an dasselbe statt.

Zu den Ursachen der Abkugelung der Kerngestalt in der hohen Temperatur möchte ich folgendes bemerken. Conklin hat bei Crepidula beobachtet, daß in hoher Temperatur $\left(32-37^{\circ} \mathrm{C}\right)$ die Oberflächenspannung der Kerne herabgesetzt ist, so daß sie unregelmäßige Formen annehmen. In unserem Falle ist natürlich klar, daß die Sache umgekehrt liegen müßte und nur bei Annahme einer Erhöhung der Oberflächenspannung erklärbar wäre. Wie ich jedoch schon früher bemerkte, besagen diese Behauptungen nicht viel, so lange sich nicht direkt experimentell zeigen läßt, daß die Oberflächenspannung wirklich -verändert wird, denn ich glaube, da $\beta$ in unserem Falle eine Reizkontraktion auf Grund einer Kontraktilität des Kernes vorliegt, die ebensowenig wie die Kontraktion der Filopodien der Protozoen auf einfáche Oberflächenspannungsveränderungen zurückgeführt werden dürfen. Damit soll jedoch nicht bezweifelt werden, daß der Kern als Gebilde, das doch im allgemeinen keine besondere Bewegungsaktivität entfaltet und Aktivität 
den Einfluß höherer T'emperatur auf Morphologie und Cytologie der Algen. 623

der Form aufweist, nicht rein physikalisch durch einfache Änderung der Oberflächenspannung zum umgebenden Medium seine Gestalt etwas verändern kann wie im Falle Conklins, in unserem Falle jedoch scheint mir aktive Kontraktilität vorzuliegen.

\section{Tabellaria fenestrata Kützg. \\ (Taf. XVII, Abb. 28, 29.)}

Das Material wurde am 20. März gesammelt. Diese Diatomee verträgt eine Temperatur von $31^{\circ} \mathrm{C}$ nur einige Tage. Die Chloroplasten verkleinern sich in der Wärme bedeutend und nehmen eine offenbar dichtere Konsistenz an, da sie auch stärker lichtbrechend sind, sie verlieren auch ihre feingranuläre Struktur und werden mebr homogen. Diese Veränderungen lassen sich am besten verstehen, wenn wir Wasserabgabe und Dichterwerden der Struktur als Ursache annehmen. Teilungen finden in fertigen Zellen wohl keine statt, da ihre Anzahl gegenüber der Kälte nicht verändert erscheint. Der Kern, der ín der Kälte ein Bläschen erfüllt von kleinen Chromatinkörnern und mit einem großen Nukleolus darstellt, verliert in der Wärme schon nach einem Tage bedeutend an Volumen, wobei er offenbar Caromatin abgibt, das sich längs dem Plasmawandbelag der Zelle in Körnchenform nachweisen läßt und besonders in Kernnähe dichter angehäuft ist.. Nukleolus ist noch vorhanden. Nach zwei Kulturtagen enthält der Kern nur mehr einige grobe Chromatinbrocken und kleinere durch seine Größe unterschiedenen Nukleolus, schlie日lich kollabiert er unter dem Druck der C'aloroplasten und seine Chromatinkörner verstreuen sich zwischen denselben. Wir beobachten also hier langsamen, vollkommenen Schwund des Kernes. $Z u$ bemerken ist noch besonders, da $B$ dieser ganze Proze $B$, der übrigens nicht in allen Zellen gleich weitgehend ist, in der le benden Zelle stattfindet, die so ihres Kernes unter Umständen verlustig geht und dann jedenfalls früher oder später zugrunde geht.

Meridion circulare verhält sich.im wesentlichen so wie Tabellaria, leider habe ich diese Art nicht genauer untersucht.

\section{Diatoma hiemale Kützg.}

(Taf. XVII, Abb. 30, 31.)

Diese Diatomee ist als typische Kaltwasserform gegen Temperaturerhöhung sehr empfindlich, sie wurde deshalb nur bei etwa $23^{\circ} \mathrm{C}$ gehalten und lebte auch da nur einige Tage, da sie an fließendes, eiskaltes Quellwasser gewöhnt ist.

Nach zwei Kulturtagen zeigt sie folgende Veränderungen. Die C.sromatophoren, die in der Kälte (Abb. 30) gro $B$ und ausgebreitet sind und oft amöboide Form besitzen und je ein großes Pyrenoid aufweisen, haben sich mehr weniger kontrahiert (Abb. 31), eine Substanzverminde- 
rung kommt wohl weniger in Frage. Die Pyrenoide haben starken Substanzschwund erfahren und sind sehr undeutlich geworden.

Der Kern ist im Kältematerial in der Zellmitte an Plasmafasern aufgehängt, bläschenförmig, mit großem Nukleolus und feiner Chromatinstruktur. In der Wärme findet mehr minder lebhafte Caromatinemission auf dem Wege der plasmatischen Aufhängefasern statt, wobei der Nukleolus oft vollständig aufgelöst wird und der Kern zuletzt nur ein kleines, substanzarmes Bläschen, das. oft zwischen den Chromatophoren fast zerdrückt wird, darstellt.

\section{Cymbella spec. \\ (Taf. XVII, Abb. 32, 33.)}

Diese Gattung erweist sich als außerordentlich eurytherm. Sie wurde am 20. März in etwa $5^{\circ} \mathrm{C}$ kaltem Wasser gesammelt und konnte tagelang ohne Schaden bei $31^{\circ} \mathrm{C}$ kultiviert werden. Nach 3 Tagen wurden, ohne daß die geringste Abnahme der Vitalität festzustellen gewesen wäre, die Versuche abgebrochen.

Während Chromatophoren und Kern sich in der Kälte sehr intensiv mit Kernfarbstoffen färben, bleiben die Exemplare der Warmkultur deutlich lichter. Die Cinromatophoren sind dünner und zarter und weisen eine feine Längssteifung auf (Abb. 33). Das Pyrenoid ist besonders an dem Kältematerial deutlich erkennbar und. weist die von Schmitz beschriebene Lagerung auf. Der Kern, ebenso wie die zwei Nukleolen, erfahren in der Wärme eine ziemlich bedeutende Größenrełuktion. Die Caromatinstruktur wird lockerer und weniger stark färbbar (Abb. 32, 33). Interessant ist das Verhalten der Öltropfen. Wie Beyerink nachgewiesen hat, stellt es das Assimilationsprodukt der Diatomeen dar. Bei ungünstigen Wachstumsbedingungen findet eine Anhäufung desselben statt, nicht aber bei raschem Wachstum. Meine Exemplare hatten allerdings sowohl in hoher als niederer Temperatur reichlich Öltropfen eingelagert. Nach Mereschewsky entstehen die großen Ölkugeln durch die Leistung sog. Eleioplasten, sie sind also zunächst teilweise lebende Gebilde. In der Wärmekultur besitzen die Kugeln meist extrem große Zentralvakuolen, stellen also nur eine dünne Olschale dar, demgemäß sind sie auch viel größer und erfüllen die Zelle auch in höherem Maße als in der Kälte. Ihre Zahl scheint jedoch im Mittel nicht vermehrt zu sein.

Obgleich es keinem Zweifel unterliegen dürfte, daß diese Vakuolisation ein Zeichen dissimilatorischen Verbrauches bzw. Uberführung in eine andere Form ist, so ist doch auffallend, daß nach 3 Tagen Kulturdauer in so hoher Temperatur nicht überhaupt alle, auch vakuolisierte Öltropfen verschwunden sind. 
den Einfluß höherer Temperatur auf Morphologie und Cytologie der Algen. 625

\author{
14. Synedra spec. \\ (Taf. XVII, Atb. 3ł, 35.)
}

Diese Art ist wenig temperaturbeständig. Schon nach 2 Tagen sind die meisten bei $31^{\circ} \mathrm{C}$ Kulturtemperatur abgestorben. Die Kälteexemplare wurden am 20. März in Wasser von $5^{\circ} \mathrm{C}$ gesammelt.

Vor allem ist die Kontraktion der Chromatophoren in der Wärme hervorzuheben (Abb. 35), die offenbar als Reizreaktion aufzufassen ist. Während diese in der Kälte die ganze Zellänge in Gestalt zweier wandständiger Platten, die in der Mitte zusammenstoßen, einnehmen, ziehen sie sich in hoher Temperatur gegen die Mitte der Zelle zusammen und lassen die beiden Zellenden ein beträchtliches Stück frei. Demgemäß drängen sie sich auch in der Mediane stärker zusammen und auf diese Weise wird der zwischen ihnen befindliche Kern meist zu einem dünnen chromatischen Faden zusammengedrückt.

Der Kern enthält in niederer Temperatur einen großen Chromatinnukleolus und mehrere große Chromatinbrocken (Abb. 34), während in der Wärme alle schwinden und nur einige ganz kleine Chromatinbrocken sich finden (Abb. 35). Es findet offenbar auch AusstoBung chromatischer Substanz statt, da man oft viele dunkle Körner längs der freien Chromatophorenränder beobachtet.

Die Struktur der Wärmechromatophoren ist viel dichter und kompakter als die in der Kälte, was offenbar auf Wasserabgabe hindeutet. Bezüglich der Photographien Abb. 34, 35 ist nur noch zu bemerken, $\mathrm{da} B$ die eine (Abb. 34) zwei noch nicht allzulange aus einer Teilung hervorgegangene und deshalb noch schmale Zellen darstellt.

\title{
15. Navicula perpusilla Grun. \\ (Taf. XVII, Abb. ¿6, 37.)
}

Diese Form bildet auf überrieselten Brettern dichte, fast nur aus dieser Art bestehende Filze und wurde am 20. März gesammelt und 1-2 Tage bei $31^{\circ} \mathrm{C}$ kultiviert.

Die Beschaffenheit des Zellinhaltes der Kältezellen stellt sich folgendermaßen dar (Abb. 36). An den Längsseiten der Zelle befindet sich je ein plattenförmiger Chromatophor, der mit seinem Gegenüber in der Zellmitte durch eine breite, den Kern enthaltende Plasmabrücke verbunden ist. Das Plasma ist reichlich entwickelt, granuliert und mit Hämalaun ziemlich gut färbbar. Der Kern ist groß, bläschenförmig mit großem Nukleolus und groben Chromatinkörnchen.

Nach eintägigem Aufenthalt in hoher Temperatur haben Chromatophoren und Plasma starke Reduktion erfahren (Abb. 37). Beide sind mangels einer distinkten Färbung überhaupt nicht mehr als getrennt erkennbar. Diese Erscheinung der Chromatophorenreduktion, wobei 
diese ihre spezifischen Eigentümlichkeiten verlieren und mehr minder plasmaartig werden, haben wir des öfteren beobachten können. Dementsprechend hat auch die bräunliche Farbe der Algen an Intensität stark nachgelassen. Der Kern hat seinen Chromatinbestand vollständig verloren, nur der Nukleolus ist öfter noch als kleines, gefärbtes Pünktchen erkennbar - der einzige Zellbestandteil, der Hämalaun in einigermaßen bedeutendem Maße speichert. Hingegen erscheint die Liningrundlage des Kernes wie aufgequollen, was dem Kern ein stärkeres Lichtbrechungsvermögen verleiht.

Nach zweitägiger Kultur sind die Algen, obgleich meistens noch lebend, ganz der Auflösung und Erschöpfung verfallen. Der Zellinhalt besteht fast nur mehr aus Flüssigkeit, die von einem netzartigen Plasma durchzogen ist. Der Kern hat infolge des Wachstums der stark lichtbrechenden, amploidartig aussehenden Substanz eine abnorme Beschaffenheit angenommen und besteht scheinbar überhaupt nur mehr aus dieser Masse. Weitgehende Degeneration ist also das Ende der Temperaturmetamorphose.

\section{Oscillatoria princeps Vauch.}

(Taf. XVII, Abb. 38-43.)

Diese Alge wurde am 18. Mai in ungefähr $7^{\circ} \mathrm{C}$ kaltem Wasser gesammelt und hierauf 12 Stunden lang im Thermostaten bei $36^{\circ} \mathrm{C}$ gehalten. Diese kurze Zeit genügte, um interessante Veränderungen im Zellinhalte hervorzurufen. Die folgende Besprechung behandelt auf Grund - mit Caromessigsäure fixierten und mit Hämalaun gefärbten Präparaten die normalen Verhältnisse der Kälte- und Wärmekultur gleichzeitig.

Zunächst ist die Färbung in der Kälte eine satt blaugrüne; in der Wärme in verschiedenem Maße gelblichgrüne. $\mathrm{Da}$, wie wir wissen, an der Färbung der Oscillarien drei Farbstoffe beteiligt sind, nämlich Chlorophyll, Phykozyan und Carotin, so kann der Farbumschlag nur auf Abnahme bzw. Schwund einer oder mehrerer Komponenten beruhen (vgl. Kohl 1903). Es läßt sich nun leicht einsehen, daß ein Schwinden des Paykozyans die Farbe mehr ins gelblichgrüne umschlagen lassen muB. Außerdem scheint auch das Chlorophyll eine Abschwächung zu erfahren, Es ist nun interessant, daß dieser Farbumschlag auch durch Veränderung der Ernährung experimentell erzeugbar ist. Magnus und Sch ind ler zeigten, da $B$ in Kulturen, deren Nitratgehalt erschöpft ist, ein solcher Farbumschlag eintritt. Und zwar fassen diese Autoren denselben als zweckmäßige Anpassung auf, indem nämlich dadurch Herabsetzung der Assimilation durch die Chromatophoren und mithin eine Art Ruhestadium gemäß den ungünstigen Bedingungen eintritt. Würde nämlich bei Stickstoffmangel die Assimilation weitergehen, es aber infolge des Salzmangels zu keinem Wachstum kommen können, so müßten 
schwere Stauungen und Anhäufungen auftreten und anderseits würden aber die Zellen bei dem Versuche zu wachsen infolge des Nährsalzmangels sich vollkommen erschöpfen. Mit der Rückbildung der.assimilatorischen Farbstoffe aber ist dem allen abgeholfen - die Zelle geht in ein Ruhestadium ein. Genauer hat Boresch diese Sache untersucht. Auch er findet das Fehlen der Nitrate im speziellen als Ursache des Farbenumschlages. Dieser beruht auf dem Abbau des Chlorophylls und Phykozyans, wobei im wesentlichen bloß das Carotin zurückbleibt. Das neuerliche Ergrünen bei Nitratzugabe erfolgt am besten bei einer Temperatur von etwa $20^{\circ} \mathrm{C}$. Durch hohe Temperatur wird es wieder gehemmt, ebenso durch tiefere. Es ist nun nicht wahrscheinlich, daß in meinen Experimenten, die doch nur 12 Stunden dauerten, der Farbumschlag infolge Nährsalzmangels eintrat. Es wird sich offenbar um einen infolge der hohen Temperatur besonders beschleunigten dissimilatorischen Verbrauch der Farbstoffe handeln, deren Neubildung, wie wir aus den Ergebnissen von Boresch schließen müssen, bei so hoher Temperatur zu langsam - wenn überhaupt - erfolgt, um die Zersetzung kompensieren zu können.

Die Zerbrechlichkeit der Fäden ist in hoher Temperatur außerordentlich gesteigert, sie macht sich nicht nur am lebenden Material, sondern auch noch am fixierten und gefärbten in außerordentlichem Maße geltend. Es scheint also sowohl das Plasma als besonders die Zellmembran in der Wärme eine bedeutende Elastizitätsverminderung zu erfahren. Infolge intensiveren Wachstums sind die Zellen im allgemeinen in hoher Temperatur etwas länger als in der Kälte.

Das Kälteplasmastellt sich als fast nichtfärbbare, feinwabige und sehr zarte Masse dar (Taf. XVII, Abb. 40, 41), während das Wärmeplasma meistens gröberen Wabenbau (Abb. 42), der sogar ganz extreme Grade zeigen kann, aufweist (Abb.43). Die Wabenwände treten wegen der stärkeren Brechkraft des Wärmeplasmas viel schärfer von ihrem Inhalt hervor, meistens ist außerdem das Plasma in der Wärme stärker färbbar, was auf feinverteilte, in der Kälte mehr lokalisierte Substanzen vielleicht chromatischer Natur hinweist. Das starke Lichtbrechungsvormögen des Wärmeprotoplasmas, das offenbar auf Wasserarmut hindeutet, ist wahrscheinlich durch die wasseranziehende Wirkung der osmotischen aktiven Dissimilationsprodukte bedingt. Diese sammeln sich in den Wabenräumen ein und attrahieren das Quellungswasser des umgebenden Plasmawabenwerkes. Wenn man will, kann man die so zustande kommende Vergrößerung der Plasmaalveolen schon als Plasmavakuolisation ansprechen (Abb.43), empfehlenswert ist das aber nicht, da es sich ja nur um stark vergrößerte Alveolen handelt, die jedoch noch nicht allzusehr sich von deren Normalmaßen entfernen. Große Vakuolen, die nach Kohl ein Kennzeichen des Alters und der 
Degeneration sind, kommen in meinem Material nur selten zur Beobachtung; nach Kohl treten solche zahlreich in Dunkelkulturen auf.

Nach alledem.wird man also mit Kohl die Cyanophyceenzelle sowohl in der Kälte als in hoher Temperatur - wo ja nur eine Vergröberung des alveolaren Baues stattfindet - mit den meristematischen Zellen höherer Pflanzen vergleichen dürfen, aber im Betreff der Vakuolisation weicht sie bei Temperaturerhöhung von diesen ab.

Einen allgemeinen Uberblick über die Anordnung und Stärke der Färbbarkeit der mit Kernfarbstoffen tingiblen Substanz (Chromatin und Zentralkörner) geben die Photographien Abb. 38, 39. In der niederen Temperatur (Abb. 38) hebt sich der intensiv gefärbte Zentralkörper (Kern) deutlich vom umgebenden Plasma ab, während in der Wärme (Abb. 39) das nicht der Fall ist, da hier einmal Abnahme der Kernfärbbarkeit und seiner Einschlüsse, anderseits Zunahme der Plasmafärbbarkeit vorliegt. Nur einige gröbere Granula im Zellzentrum deuten auf den Zentralkörper hin (Abb. 39), hingegen ist seine feinere Gestalt jetzt deutlicher zu erkennen. Die typische Zellstruktur in der Kälte zeigt Abb. 40 in stärkerer Vergrößerung. Der Zentralkörper als dunkel gefärbte, chromatinreiche Masse ist im Zellzentrum am schmalsten, und breitet sich dann meist an den Querwänden mehr aus. Dort findet auch besonders die Ablage der in ihm befindlichen Zentralkörner (vgl. Kohl) statt, die meist ziemlich klein sind, aber scharf und dunkel gefärbt erscheinen. Sie fehlen nur am natürlichen Fadenende, treten nach rückwärts davon bald auf und gehören zu den normalen Bestandteilen der Zelle. Seltener finden sich Bilder wie Abb. ${ }^{1}{ }^{1}$ ). Hier ist es zu einer eng lokalisierten Anhänfung der Zentralkörner an den Quer. wänden der Zelle gekommen und zwar, wie eine genauere Beobachtung lehrt, ist die beiderseitige Anhäufung an jeder zweiten Querwand eine besonders massige. Der mittlere Teil der Zelle, der die Hauptmasse des Zentralkörpers enthält, ist in diesen Fällen der extremen Abscheidung von großen Zentralkörnern schwächer gefärbt, da er nur das Chromatin aber keine Zentralkörner in diesem Teile enthält. So besteht also eine gewisse Reziprozität zwischen der Färbbarkeit des mittleren Zentralkörpers und der Körneransammlung an den Zellquerwänden. In den Wärmekulturen findet nun Schwund der Zentralkörner statt, die immer blasser und kleiner werden und endlich überhaupt nicht mehr sichtbar

1) Da wir wissen (vgl. Kobl), daß die Zentralkörner, wie sie etwa Abb. 40 zeigt, eine Strecke weit hinter dem Spitzenende des Fadens auftreten, ist es wichtig zu bemerken, daB Abb. 41 nicht etwa gegenüber $A b b .40$ ein noch weiter rückwärts gelegenes Fadenstück darstellt, sondern ein typischer Ausschnitt eines Fadens darstellt, der sich in der allgemeinen Hypertrophie der Zentralkörner von der Mehrzahl der anderen typischen Fäden unterscheidet, trotzdem aber nicht gerado zu den großen Seltenheiten gehört. 
sind, dagegen färbt sich das ganze Protoplasma besonders an den Wabenknotenpunkten viel dunkler (vgl. Abb. 42, 43). Dieser Schwund der Zentralkörner, die den Volutanskugeln der Bakterien entsprechen, offenbar Reservestoffe darstellen und dementsprechend zuerst verbraucht werden, worauf erst Plasmareduktion erfolgt, ist von mehreren Autoren bei gesteigertem Stoffwechsel oder Hunger beobachtet worden. So von Zimmermann bei hoher Temperatur. Nach KohI sind sie bei Tolypothrix im Sommer selten, im Winter' häufig. Diesbezüglich angestellte vorläufige Experimente mit hoher Temperatur, oder in zweimonatiger Dunkelkultur, unter deren Bedingungen sich Abnahme der Zentralkörner konstatieren ließ, haben seine Ansicht bestätigt, daß diese Gebilde und die Cyanophycinkörner als Reservestoffe bei gesteigertem dissimilatorischen Stoffverbrauch und beim Wachstum verbraucht werden, so daß sie schließlich überhaupt nicht mehr zu finden sind.

Was den Zentralkörper selbst, der als Kern der Cyanophyceenzelle anzusehen ist, betrifft, so stellt er (vgl. Kohl) in der Kälte ein lappig

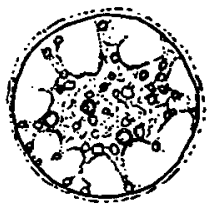

Abb. 1.

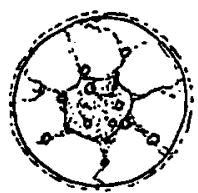

Abb. 2.

0 scillatoria princeps Vauch. Optischer Fadenquerschnitt, Vergr. 2100. Abb. 1 Kältematerial $\left(7^{\circ} \mathrm{C}\right)$. Abb. 2 12stündige Wärmekultur bei $36^{\circ} \mathrm{C}$. (Umrisse des Kernes, Zentral- und Chromatinkörner halbschematisch.)

verzweigtes Gebilde verschiedenster Form dar (Textabb. 1) und breitet sich meist an den Querwänden der Zellen etwas aus. Er enthält außer den Zentralkörnern die chromatische Substanz, die auf ein schwach färbbares Kerngerüst in Granulaform aufgelagert ist: Eine Membran ist nicht distinkt färbbar. Unter Umständen kontrahiert er seine Fortsätze mehr weniger und erscheint dann schärfer abgegrenzt, im allgemeinen jedoch tritt er wegen seines Reichtums an Fortsätzen, die nicht immer deutlich erkennbar sind, nicht scharf hervor. Anders ist das in der Wärmekultur. Hier ist er immer mehr minder abgerundet (Textabb. 2), was in Anbetracht des Umstandes, daß nach derselben Präparationsmethode im Kältematerial die Fortsätze immer erhalten bleiben, nicht auf Rechnung der Fixierung, sondern auf aktive vitale Kontraktion in der Wärme zurückzuführen ist. Sein Volumen ist bedeutend kleiner geworden (in 12 Stunden!), auch hebt er sich manchmal recht deutlich von seiner Umgebung ab, trotzdem er durch Chromatinreduktion und Zentralkörnerschwund bedeutend an Färbbarkeit verloren hat. Eine Kernmembran ist unter diesen Umständen noch am ehesten sicht- 
bar, wenn auch nur als scharfe Grenzlamelle des Gebildes. In Photographie 43 ist in einigen Zellen der Kern ganz gut als bläschenförmiges Gebilde mit dunkler Kontur sichtbar. In anderen Fällen allerdings - und das ist die Mehrzahl - ist er in dem dunklen und homogenen oft von blasser Granula erfülltem Plasma überhaupt nicht erkennbar (Abb. 42).

Als Endstadium der Temperaturveränderung innerhalb einer Versuchsdauer von 12 Stunden sind die Zellen überhaupt fast gar nicht mehr färbbar und zeigen nur mehr vereinzelte, etwas dunkler gefärbte Einschlüsse. Im allgemeinen machen sie einen fast homogenen, nur schwach alveolären Eindruck.

Zunächst verliert also in der hohen Temperatur die Zelle ihre Reservestoffe (Zentralkörner), dann beginnt die Plasma- und Chromatinreduktion und endlich ist offenbar überhaupt fast alles aufgebraucht und die Zelle einer vollständigen Erschöpfung nahe. Es verhält sich also im allgemeinen die Cyanophyceenzelle sowohl was die Kerngröße, als was Plasma, die Reservestoffe und das Chromatin betrifft sowie die Zelle höherer Pflanzen und vieler Algen. Sie besitzt auch eine typische, temperaturvariable Kernplasmarelation.

\section{B. Zusammenfassung der allgemeinen Resultate.}

Die Temperaturerhöhung innerhalb der von mir untersuchten Grenzen ist in der Mehrzahl der Fälle als rein physiologische zu bewerten, obgleich tiefgreifende morphologisch-cytologische Veränderungen vorliegen, die sich jedoch alle auf eine Verschiebung des physiologischen Gleichgewichtes, nicht aber - wie das bei Einwirkung anderer experimenteller Faktoren, wie Chemismus usw. stattfindet - auf schwere Störungen, Vergiftungen zurückführen lassen, sondern in der Mehrzahl der Fälle bloß Veränderungen im gegenseitigen Verhältnisse und Intensität normaler, assimilatorischer und dissimilatorischer Prozesse bedeutet.

Die Resistenz der verschiedenen Formen, d. h. die Fähigkeit eine gewisse Zeit in hoher Temperatur zu leben und die Zellen zu teilen, ist stark verschieden: sie ist groß bei manchen Spirogyren, bei Mougeotia, Cymbella, Desmidium, Oscillatoria; sehr klein bei.Zygnema, Ulothrix, Diatoma; eine mittlere bei den übrigen untersuchten Formen.

Die Einwirkung der Temperaturerhöhung auf die morphologisch-cytologischen Verhältnisse erweist sich, obgleich meist ziemlich tiefgreifend, doch nur bei sehr. temperaturempfindlichen Arten als an der Grenze des pathologischen liegend; ausgesprochen degenerativ verhält sich Ulothrix, die auch als einzige Alge Turgorerniedrigung als Kriterium starker Schädigung erkennen läßt. 
den Einfluß höherer Temperatur auf Morphologie und Cytologie der Algen. 631

Das Zentrum und der Ausgangspunkt aller morphologisch cytologischen Veränderungen und Prozesse ist die allgemeine physiologische Wirkung hoher Temperatur. auf die Stoffwechsəlbilanz an sie nicht angepaßter Organismen. Der Erhaltungsumsatz, d. h. die Menge der veratmeten Stoffe, ist nicht nur absolut, sondern auch relativ bedeutend gesteigert. Die Assimilationskurve ist nämlich eine Maximumkurve, die also bei allzuhoher Temperatur einen Abfall aufweist, während die Atmung dauernd, und sogar bei hohen Temperaturen unverhältnismäßig stark ansteigt. So kommt es nicht nur zu einem baldigen Verbrauch der Reservestoffe, deren Neuproduktion weit hinter dem Verbrauch zurückbleiben muB, sondern es findet eine Selbstverbrennung der lebenden Substanz im engsten Sinne des Wortes statt, so zwar, da $B$ die bedeutende Massenreduktion oft bis zum völligen Schwund geht, während Hand in Hand damit oft rasches Zellwachstum oder Vakuolisation infolge der Zunahme osmotisch wirksamer Stoffe im Zellsaft einhergeht. In manchen Fällen verbraucht sich so die lebende Substanz selbst bis zum letzten Rest, ohne da $B$ früher Absterbeerscheinungen $\mathrm{zu}$ bemerken sind.

Die Individualvariation in dem Grade der morphologischen Veränderungen - wir denken besonders an Spirogyra, die ja die interessantesten Verhältnisse darbietet - ist in hoher Temperatur bedeutend, was darauf hinweist, da $B$ je nach dem inneren physiologischen Zustand, stattfinden von Teilungen usw. der Temperatureinfluß sehr verschieden weitgehend sich geltend macht. Erhöhung der individuellen Variationsbreite in hoher Temperatur oder ungünstigen Lebensbedingungen ist von Paal bezüglich der geotropischen Reaktionszeit, von Peter für die tierische Embryogenese und von mir bezüglich der Wirkung von sehr hoher Temperatur auf morphologisch-cytologische Veränderungen bei Phanerogamenwurzeln beobachtet worden.

Im einzelnen sind folgende Veränderungen bei hoher Temperatur (meist etwa $30^{\circ} \mathrm{C}$ ) hervorzuheben.

Die Zellänge erfährt infolge der Zunahme osmotisch wirksamer Substanzen des Dissimilationsprozesses oft eine bedeutende, und da die Membran dabei dünner wird, rein passive Streckung (Oscillatoria, Mougeotia, Zygnema, Oedogonium, besonders Spirogyra). Eine Zunahme der Zellgröße findet sich auch bei Protococcus. Im Falle der Fadenalgen ist (mit Ausnahme von Oscillatoria) die Zellstreckung durch die osmotische Wasseraufnahme der Zentralvakuole bedingt, während bei Oscillatoria und Protococcus Vakuolisation und Schaumstruktur des Plasmas selbst auftritt; dieses also seine Dissimilate nicht in die Zentralvakuole, sondern in sich selbst ablagert. Bei Spirogyra beruht auf der raschen Zellstreckung nach einer Teilung der, infolge der herabgesetzten Stoffwechselökonomie, eine Produktion neuer lebender Substanz nicht folgen 
kann, die intensive Veränderung in Gestalt-Anordnung der Chromatophoren.

Die Reservestoffe - besonders Stärke, Ol, Zentralkörner der Oscillarien - werden natürlich in hoher Temperatur sofort aufgebraucht und sind schon nach einem Tage meist fast ganz verschwunden, so daß nunmehr ausschließlich Selbstverbrennung des Plasmas stattfindet. Auch bei Oscillatoria findet Schwund der Zentral- und Cyanophycinkörner schon nach 12 Stunden in $36^{\circ} \mathrm{C}$ statt.

Chromatophoren. Diese werden bei Spirogyra durch das starke und rasche Zellwachstum nach der Zellteilung, der kein solches der Chromatophorenmasse parallel geht, einfach mehr minder in die Länge gestreckt, so daß sie bei Arten mit normal stark gewundenen Gebilden oft'ganz gerade die Länge der Zelle durchziehen, was auf eine Spannung ihrer Substanz, zumindest während des Streckungsprozesses, hindeutet. Der Grad dieser Veränderung in Gestalt und Anordnung ist offenbar von der Anzahl der in der Wärme erfolgten Zellteilungen abhängig, ja überhaupt durch das Stattfinden derselben bedingt, indem je öfter die fast nicht wachsende Chromatophorensubstanz geteilt und wieder auf normale oder gar übermäßige Zellänge gebracht werden muß, sich ihre Gestalt immer mehr einer Geraden annähert. Auch bei Mougeotic findet eine Spannung und Dehnung der Platten infolge des alleinigen Streckungswachstums der Zelle statt, indem der Chromatophor infolge der Spannung in der Mitte meist eingezogen erscheint, am Ende aber oft nur mit je einem Zipfel in den vier Zellecken aufgehängt ist.

Die physikalische Beschaffenheit. der Chromatophoren bei" Spirogýra nähert sich mehr dem flüssigen Zustand, indem die innere Festigkeit der Bänder entsprechend abnimmt, darauf deuten leicht Abschnürungen von Teilstücken, unregelmäßige, oft inverse Windungen, Fusionen zweier Bänder an einer Berührungsstelle, Ausstülpungen der Cnromatophorensubstanz durch den Zug der ansetzenden Plasmafasern, Verdickung der Bänder in Kernnähe beruhend offenbar auf Hinzufließen eines Teiles der Substanz, und die endlich schon ans Pathologische grenzende, am besten als Zerschmelzung in viele kleine Teile zu bezeichnende Erscheinung. Eine sekundäre Verfestigung ist seltener.

Der Substanzschwund der Chromatophoren in hoher Temperatur ist allgemein verbreitet. Bei Spirogyra verlieren die Bänder ihre zackige Kontur, werden mehr minder walzenförmig und zeigen eine deutliche faserige Struktur, Reizkontraktion verbunden mit starkem Substanzschwund beobachten wir bei Zygnema, Desmidium, Vaucheria, Tabellaria, Diatoma, Synedra; wo überall mit Ausnahme der ersten zwei Arten ein Dichterwerden der Struktur auf Wasserabgabe hindeutet. Bei Protococcus findet Vakuolisation, die schließlich in ein locker spongioses Netzwerk übergeht, als Reduktions- und Desintegrationsvorgang 
den Einfluß höherer Temperatur auf Morphologie und Cytologie der Algen. 633

statt, bei Mikrospora und Oedogonium schwindet die Chromatophorensubstanz fast vollkommen und ist endlich vom Plasma überhaupt bei ersterer Art nicht mehr unterscheidbar.

Farbe. Die Farbe der grünen Algen nimmt bedeutend an Intensität ab, auch bekommt sie einen deutlichen Stich ins gelbliche. Ebenso geht die Farbe des Oscillarien in ein schmutziges Gelblichgrün über. Die Chromatophorenfarbstoffe werden einerseits offenbar nicht mehr stetig neu gebildet oder nur in unzureichendem $\mathrm{Maße}$, anderseits unterliegen sie einer starken Zersetzung. Natürlich muß auch die starke Abnahme der Ciromatophorenmasse farbherabsetzend wirken.

Die Zellwand wird nach jeder Teilung in der hohen Temperatur mfolge des starken Streckungswachstums der Zellen und fehlender Substanzneubildung durch Dehnung stark verdünnt, natürlich um so mehr, je öfter in der Wärme Zellteilungen erfolgen. Es ist damit ein Beweis dafür erbracht, daß Zellwachstum durch ausschließliche Membrandehnung und plastische Utberdehnung ohne Substanzan- oder -einlagerung allein durch die Turgorkraft stattfinden kann. Es scheint jedoch auch eine chemische Veränderung der Zellwände in hoher Temperatur zu erfolgen, denn sie färben sich mit Hämalaun nicht mehr, während sie in der Kälte mehr minder stark damit gefärbt erscheinen. Auch die Br üchigkeit der Fäden, die sich in leichtem Zerfall bei mechanischen Insulten äuBert und sehr vermehrt ist, deutet auf eine Veränderung der Membranbeschaffenheit hin (Spirogyra, Oscillatoria). Es wäre - im Anschlu $B$ an die Theorie von Reinhard t - möglich, da B die Zellwand in der Kälte mehr minder lebende Plasmabestandteile enthält, die ein Wachstum der Membran durch Substanzein- und -anlagerung ermöglichen, da $\measuredangle$ diese jedoch infolge des starken Plasmaschwundes ebenfalls verschwinden und so das reine, nicht mehr zu aktivem Wachstum befähigte, auch sehr brüchige Zelluloseskelett übrig bleiben würçe.

Das Protoplas ma erleidet bedeutende Reduktionen. Manchmal (Spirogyra, seltener Oedogonium) kommt es zur Abschnürung von Plasmaklümpchen, die sich stark vakuolisieren und offenbar als Degenerationsprodukte aufzufassen sind. Eine starke, schaumartige Vakuoli sation größerer Plasmapartien kommt manchmal bei Oedogonium vor. Das spricht für die sichere Möglichkeit der absoluten Neubildung von Vakuolen offenbar aus Alveolarräumen. Bei Oscillatoria findet eine Vergröberung und Verdeutlichung der Alveolarstruktur des Plasmas statt, die sich jedoch in Anbetracht ihrer absoluten Feinleit und Gleichmäßigkeit nicht als Vakuolisation bezeichnen läßt. Das Plasma erweist sich infolge der Wasserentziehung durch im Zellsaft befindliche, hoch osmotisch aktive Stoffe stärker lichtbrechend und dichter (Oscillatoria). Es enthält (Spirogyra, Oedogonium) oft stark lichtbrechende, ebenso färbbare, kleinste Körnchen, die im Sinne Lepeschkins (69) in der 
Mehrzahl der Fälle als infolge der hohen Temperatur an Zahl vermehrte Denaturierungsprodukte und physiologische Gerinnungsprodukte des Plasmas aufzufassen sein dürften.

Bei mancher Spirogyra-Art findet Zusammenballung eines großen Teiles des Plasmas zu einer ziemlich großen, kugeligen Masse statt, was an die Wundreaktion des Plasmas benachbarter Zellen in Zwiebelschalenepidermen erinnert und wie dort offenbar als temperaturbedingte Reizreaktion aufzufassen ist.

Die Pyrenoide erleiden fast allgemein eine starke Verkleinerung, i mmer sind sie schwächer färbbar und substanzarm. Manchmal schwinden sie ebenso wie das Plasma so gut wie ganz (Oedogonium). Obwohl Teilungen dieses Gebilde in hoher Temperatur stattfinden, so vermindert sịch trotzdem infolge der starken Abnahme der pro Zelle entfallenden Chromatophorenmasse ihre Anzahl in jeder Zelle (Spirogyra).

Der Kern zeigt bei Spirogyra oft eine exzentrische Lage, indem er mehr wandständig ist. Bezüglich der Gestalt zeigt er Veränderungen nur bei Oscillatoria und Microspora. Bei letzterer kontrahiert der Kern in der Wärme seine zahlreichen rhizopodenartigen Fortsätze und kugelt sich ab. Bei Oscillatoria findet ebenfalls eine Einziehung der reichen Verzweigungen und Ausstülpungen statt, so daß der Kern mehr minder Kugelform annimmt.

Die Kerngröße ist allgemein einer Abnahme unterworfen, die oft sehr bedeutend ist. Auch für Oscillatoria gilt dieșe Abnahme der Kernplasma- bzw. Kernzellrelation was in Anbetracht der eigenartigen, lange strittigen Natur des Kernes der Cyanophyceen bemerkenswert ist, denn es zeigt, daß sich die Zentralkörper dieser Algen auch was ihr experimentell-cytologisches Verhalten höherer Temperatur gegenüber betrifft, ganz so wie die Kerne der Grïnalgen, höheren Pflanzen und Tiere verhalten.

Infolge starker Wasseraufnahme durch osmotisch wirkende Zerfallsprodukte sich abbauenden Chromatins findet in manchen Fällen (z. B. Mougeotia) auch Vergrößerung des Kernes in hoher Temperatur nach längerem Aufenthalte statt, die jedoch oft schließlich einer Kollabierung und Schrumpfung Platz macht. Vergrößerung des Kernes bei den höchsten Temperaturen ist von mir als sekundäre Erscheinung bei Phanerogamen nachgewiesen und theoretisch beleuchtet worden.

Das Chromatin erfährt bedeutenden, oft nahezu vollständigen Schwund, oft durch Abgabe in gelöster Form, meist in der Art der sog. Chromatinemission in Substanz. Bei hoher Temperatur findet meist eine Zusammenballung der feinen Chromatingranula und Vergröberung der Struktur statt (Microspora, Spirogyra). Die Chromatinemission besteht nun darin, daß kleinere oder größere Chromatinpartikeln aus dem Kern direkt ins ùmgebende Plasma tıèten, 
den Einfluß höherer Temperatur auf Morphologie und Cytologie der Algen. 635

was oft sehr reichlich stattfindet (Spirogyra, Tabellaria, Diatoma) und sich dann längs der Chloroplasten und Plasmafäden in der ganzen Zelle verbreiten (besonders schön bei Spirogyra). Diese Emission ist als Regulationsprozeß zur Verminderung der Chromatinmenge in hoher Temperatur - deren Reduktion unter diesen Bedingungen im gesamten Organismenreich eine physiologische Notwendigkeit zu sein scheint aufzufassen und also ein Beispiel dafür, daß der Chromatinabgabe, nicht immer wenigstens, eine höhere, morphogenetische Bedeutung im Sinne einer Leitung und Formierung von Zelldifferenzierungen innezuwohnen braucht.

Die Kerne sind nach längerem Verweilen in der hohen Temperatur oft ganz ausgebla ßt und fast nicht mehr chromatisch gefärbt (Mougeotia). Bei Diatomeen findet oft ein so weitgehender Schwund des Kernes statt, daß schließlich nur mehr ein kleines, unregelmäßiges Häufchen loser C'nromatinkörner zwischen den Chromatophoren liegt (Diatoma, auch Protococcus). Manchmal (Tabellaria) schwindet auch dieser Rest vollkommen, so daß sich damit die lebende Zelle dem unvermeidlichen Tode ausgeliefert hat.

Der chromatische Nukleolus verkleinert sich (auch bei Spirogyra) und erleidet oft bedeutenden Substanzverlust, ganz wie das granuläre Kernchromatin. Meist ist es sogar ziemlich stark vakuolisiert (Mougeotia), manchmal scheint es sich ganz aufzulösen (Diatoma). Vakuolisation und Verkleinerung findet sich auch bei den achromatischen Nukleolen der höheren Pflanzen und der Tiere als typisch.

Bei Rücktransport in niedere Temperatur $\left(3-5^{\circ} \mathrm{C}\right)$ nachdem die hohe Temperatur starke und typische Veränderungen hervorgerufen hat, erholen sich bei Spirogyra einige Fäden schon nach einigen Stunden und speichern reichliche Stärke. Nach Zellteilungen bleiben die Zellen infolge des ganz geringen Wachstums in so niederer Temperatur, die nach der hohen Temperatur offenbar doppelt stark die Stoffwechselprozesse hemmt, kurz und führen demgemä $B$ eng gewundene Chlorophyllbänder.

Viele Fäden aber sind auch nach 7 Tagen in niederer Temperatur noch ohne Stärke und erscheinen vom Temperaturwechsel nicht berührt, denn sie weisen unverändert die Wärmecharaktere auf. Offenbar hat ihre Assimilationsfähigkeit bzw. die Fähigkeit neues Chlorophyll in genügender Menge zu produzieren dauernd gelitten. Trotz ihrer offenbar - wenn überhaupt - außerordentlich geringen Assimilation können sie aber dank der niederen Temperatur längere Zeit am Leben bleiben. Schließlich aber sterben sie wohl ab.

Graz, im September 1917. 


\section{Literaturverzeichnis.}

1. Andreesen, A., Beiträge zur Kenntnis der Physiologie der Desmidiaceen. Flora. Bd. 99. 1909.

2. Artari, A., Zur Frage über die Wirkung des Mediums auf die Form und Entwicklung der Algen. Zeitschr Kais. Moskauischen Polytechn. Hochschule. 1903. (Ref.)

3. Benecke, W., Mechanismus und Biologie des Zerfalls der Conjugatenfäden in die einzelnen Zellen. Jahrb. f. wiss. Bot. Bd. 32.

4. Berthold, G., Beiträge zur Morphologie und Physiologie der Meeresalgen. Jahrb. f. wiss. Bot. Bd. 13. 1882.

5. Beyernik, M. W., Das Assimilationsprodukt der Kohlensäure in den Chromatophoren der Diatomeen. Rec. trav. bot. Neerl. Bd. 1. 1914.

6. Biedermann, W., Physiologie der Stütz- und Skelettsubstanzen. Winter steins Handb. d. vergl. Physiologie. Bd. III. I. Hälfte. I. Teil.

7. Boresch, K., Die Färbung der Cyanophyceen und Chlorophyceen in ihrer Abhängigkeit vom Stickstoffgehalt des Substrates. Jahrb. f. wiss. Bot. Bd. 52. 1913.

8. Borodin, Über die Wirkung des Lichtes auf die Entwicklung von Vaucheria sessilis. Bot. Zeitg. Bd. 36. 1878.

9. Borowikow, U̇ber die Ursachen des Wachstums der Pflanzen. Biochem. Zeitschr. Bd. 48, 50. 1913.

10. Buchheim, A., Der Einfluß des Außenmediums auf den Turgordruck einiger Algen. Ber. d. d. bot. Ges. Bd. 32. 1914.

11. Bütschli, O., Über den Bau der Bakterien und verwandter Organismen. Naturhist. med. Verein zu Heidelberg, Vortrag. 1889. Leipzig. 1890.

12. Chambers, C. O., The relations of algeae to dissolved cxygen and carbondioxyde. With special reference to carbonate. Missouri bot. Garden. Vol. 23. 1912. (Ref. Just.)

13. Conelin, E. G., Exp. studies on nuclear and cell division in the eggs of Crepidula. Jourl. of the Acad. Nat. Sc. Philadelphia. Vol. 15. 1912.

14. Coniere, J., De I'action des eaux saleés sur la végétation de quelques Algues d'eau douce. Nuova Notarisia. Tom. 14. 1903.

15. Copeland, Über den Einfluß von Licht und Temperatur auf den Turgor. Halle. 1896.

16. Derschau, M. v., Zum Chromatindualismus in der Pflanzenzelle. Arch. f. Zellf., Bd. 12. 1914.

17. Desroche, P., Transformation experimentale de Vaucheria terrestris en Vauch. gemminata. C. R. Soc. Biol. 1910.

18. Ernst, A., Siphoneenstudien IV. Zur Kenntnis des Zellinhaltes von Derbesia. Flora. Bd. 931904.

19. Famintzin, A. S. Die Wirkung des Lichtes auf die Algen und einige andere denselben nahestehende Organismen. Dissertat. Petersburg. 1866. (russisch.)

20. - Wirkung des Lichtes auf Algen und andere ihnen nahe verwandte Organismen. Jahrb. f. wiss. Bot. Bd. 6.

21. - Die anorganischen Salze als Hifsmittel zum Studium niederer Organismen. Bot. Zeitg. 1871.

22. - Über die Symbiose als Mittel der Synthese von Organismen. Ber. d. d. bot. Ges. Bd. 30. 1912.

23. Fischer, A. Über den Bau der Cyanophyceen und Bakterien. 1897. 
den Einfluß höherer Temperatur auf Morphologie und Cytologie der Algen. 637

24. Georgevitch, P., Über den Einfluß extremer Temperaturen auf die Zellen der Wurzelspitze von Galtonia candic. Beitr. z. bot. Zentrbl. Bd. 25. 1910.

25. Gerassimow, J., Über ein Verfahren kernlose Zellen zu erhalten. Bull. soc. imp. Moscau. 1896.

26. - Über den Einfluß des Kernes auf das Wachstum der Zellen. Bull. soc. imp. Moscau. 1901.

27. - Die Abhängigkeit der Größe der Zellen von der Menge ihrer Kernmasse. Zeitschr. f. allg. Physiol. Bd. 1. 1902.

28. - Zur Physiologie der Zellen. Bull. soc. imp. Nat. Moscau. 1904.

29. - Über die Größe der Zelle und des Kernes. Beitr. z. bot. Zentrbl. Bd. 18. 1904.

30. Guyer, O., Beitrag zur Biologie des Greifensees, mit besond. Berücksichtigung der Saisonvariation von Ceratium hirundinella. Arch. f. Hychobiol. Bd. 6.

31. Haase, G., Zur Kern- und Fadenteilung von Ulothrix subtilis. Arch. f. Hydro. biol. Bd. 5.

32. Harder, R., Beiträge zur Kenntnis des Gaswechsels der Meeresalgen. Jahrb. f. wiss. Bot. (Pfeffer-Festschr.) Bd. 56. 1915.

33. Hardy, W. B., Note on differences in electrical potential with the living cell. Journ. of Physiol. Vol. 47. 1913.

34. Hartmann, O., Über das Verhältnis von Zellkern und Zellplasma bei Cera. tium und seine Bedeutung für Variation und Periodizität. Arch. f. Zellf. Bd. 14. 1916.

35. - Über das Verhalten von Zell-, Kern- und Nucleolengröße und ihrer gegenseitigen Beziehungen bei Cladoceren, während Wachstum, Generationszyklus und unter dem Einfluß äußerer Faktoren. (Eine zellphysiol. Studie.) Arch. f. Zellf. Bd. 15. 1918.

36. - Über den Einfluß der Temperaturen auf Größe und Beschaffenheit von Zelle und Kern im Zusammenhang mit der Beeinflussung von Funktion, Wachstum und Differenzierung von Organen. (Experimente an Amphibien.) Arch. f. Entw.-Mech. d. Organismen. Bd. 44.

37. - Über den Einfluß der Temperatur auf Plasma, Kern und Nucleolus und cytologische Gleichgewichtszustände. (Zellphysiol. Experimente an Pflanzen.) Arch. f. Zellf. Bd. 15.

38. - Über die experimentelle Beeinflussung der Größe pflanzlicher. Chromatophoren durch die Temperatur. Arch. f. Zellf. Bd. 15.

39. Hegler, R., Untersuchungen über die Organisation der Phycochromazeenzelle. Jahrb. f. wiss. Bot. Bd. 36. 1901.

40. Hertwig, R., Ưber neue Probleme der Zellenlehre. Arch. f. Zellf. Bd. 1. 1908.

41. - Über die physiolog. Degeneration der Protozoen. Sitzungsber. d. Ges. f. Morphol. u. Physiol. München. 1900.

42. Hieron ymus, G., Beiträge zur Morphologie und Biologie der Algen. Cohns Beiträge z. Biol. d. Pflanzen. Bd. 5. 1892.

43. Karsten, G., Die Formveränderung von Sceletonema costatum. Wissenschaftl. Meeresunters. N. F. 3. Kiel. 1898.

44. - Über farblose Diatomeen. Flora. Bd. 89. 1901.

45. Kasanowsky, V., Die Chlorophyllbänder und Verzweigungen derselben bei Spirogyra nawaschini nov. spec. Ber. d. d. bot. Ges. Bd. 31. 1913.

46. Klebs, G., Über die Organisation einiger Flagellatengruppen und ihre Beziehungen zu Algen und Infusorien. Untersuch. aus d. bot. Inst. Tübingen. Bd. 1. 1883.

47. - Beiträge zur Physiologie der Pflanzenzelle. Ebenda. Bd. 2. 1888.

48. - Utber die Bildung der. Fortpflanzungszellen bei Hydrodiction utriculatum. Bot. Zeitg. Bd. 49. 1891. 
49. Klebs, G., Die Fortpflanzung bei Algen und Pilzen. 1896.

50. - Willkürliche Entwicklungsänderungen bei Pflanzen. Jena. 1903.

51. - Über Probleme der Entwicklung. - Biol. Zentrbl. Bd. 24. 1904.

52. - Fortpflanzung der Gewächse (Physiolog.). Handwörterb. d. Naturwissenschaften. Bd. 4. S. $276 \mathrm{ff}$.

53. Kle $\mathrm{mm}$, P., Desorganisationserscheinungen der Zelle. Jahrb. f. wiss. Bot. Bd. 28. 1895.

54. Kohl, F. G., Über die Organisation und Physiologie der Cyanophyceenzelle. Jena. 1903.

55. Kolkwitz, R. Die Wachstumsgeschichte der Chlorophyllbänder bei Spirogyra. Schwandener-Festschr. 1899.

56. Krabbe, G. Über den Einfluß der Temperatur auf die osmotischen Prozesse lebender Zellen. Jahrb. f. wiss. Bot. Bd. 29. 1896.

57. Kurssanow, L., Über die Teilung der Kerne bei Vaucheria. Biol. Zeitschr. Bd. 2. 1911. (Ref.)

58. Küster, E., Beiträge zur Physiologie und Pathologie der Pflanzenzelle. Zeitschrift f. allgem. Physiol. Bd. 4. 1904.

59. Lepeschkin, W. W., Zur Kenntnis des Wachstumsmechanismus der pflanzl. Zelle. Beih. z. bot. Zentrbl. Bd. 21. 1907 .

60. - Zur Kenntnis der Einwirkung supramaximaler Temperaturen auf die Pflanzen. Ber. d. d. bot. Ges. Bd. 30. 1912; und Zur Kenntnis der Todesursache. Ebendort.

61. Liebaldt, E. Über die Wirkung wässeriger Lösungen oberflächenaktiver Substanzen auf die Chlorophyllkörner. Zeitschr. f. Bot. Bd. 5. 1913.

62. Magnus, W. u. B. Schindler, Ưber den Einfluß der Nährsalze auf die Färbung der Oscillarien. Ber. d. d. bot. Ges. Bd. 30. 1912.

63. Matrouchot, L. u. Molliard, Variations de la structure d'une algue verte sous l'influence du milieu nutritiv. Rev. gen. bot. 14. (Ref.)

64. Mereschowsky, C. Über farblose Pyrenoide und gefärbte Elaioplasten der Diatomeen. Flora. Bd. 93. 1903.

65. - Theorie der zwei Plasmaarten als Grundlage der Symbiogenesis usw. Biol. Zentrbl. Bd. 30. 1910.

66. Meyer, A. Das Chlorophyllkorn. Leipzig. 1883.

67. Nadson, G. A. Über den Einfluß der Lichtstärke auf die Färbung der Algen. Bull. Jard. imp. Bot. St. Petersburg. Bd. 8. 1908. (Russisch mit deutschem Resumée.)

68. Ně mec, B., Über experimentell erzielte Neubildung von Vakuolen in hautumkleideten Zellen. Sitzungsber. böhm. Akad. Prag. 1900.

69. - Das Problem der Befruchtungsvorgänge und andere cytologische Fragen Berlin. 1910.

70. Oltmanns, Fr., Mrorphologie und Biologie der Algen. 1904-05.

71. Paal, A., Temperatur und Variabilität in der geotrop. Reaktionszeit. Ber, d. d. bot. Ges. Bd. 31.1913.

72. Pantanelli, E., Zur Kenntnis der Turgorregulation bei Schimmelpilzen. Jahrb. f. wiss. Bot. Bd. 40.

73. Peter, K., Experimentelle Untersuchungen über individuelle Variation in der tierischen Entwicklung. Arch. f. Entw.-Mech. Bd. 27. 1909.

74. - Neue experimentelle Untersuchungen über die Größe der Variabilität und ihre biologische Bedeutung. Arch. f. Entw.-Mech. Bd. 31. 1911.

75. Pfeffer, W., Pflanzenphysiologie. 2. Aufl.

76. Ponomarew, A. P., Zur Kenntnis des Chloroplastenbaues. Ber. d. d. bot. Ges. Bd. 32. 1914. 
den Einfluß höherer Temperatur auf Morphologie und Cytologie der Algen. 639

77. Popoff, M., Experimentelle Zellstudien, I, II, III. Arch. f. Zellf. Bd. 1, 3, 4. $1908-1910$.

78. - Die Depression der Protozoenzelle und die Geschlechtszelle der Metazoen. Arch. f. Protistenkde. (Festschr. f. R. Hertwig.) 1907.

79. Rayss, T., Le Coelastrum proboscideum. Etude de Planctologie experimentale. Beiträge zur Kryptogamenflora d. Schweiz Bd. 5. 1915.

80. Reinhardt, M. O., Plasmolytische Studien zur Kenntnis des Wachstums der Zellmembran. Schwandener-Festschr. 1899.

81. Rich ter, O., Anpassung der Süßwasseralgen an Kochsalzlösungen. Flora. 1892.

82. - Zur Physiologie der Diatomeen, II. Die Biologie v. Nietzschia putrida. Denkschr. d. Mathem. naturw. Kl. Akad. Wien. Bd. 84. 1909.

83.- Die Ernährung der Algen. Monographien und Abhandl. zur internat. Rev. d. ges. Hydrobiol. u. Hydrograph. Bd. 2. 1911.

84. R ůžčka, V., Das Chromatin und Plastin in ihren Beziehungen zur Regsamkeit des Stoffwechsels usw. Festschr. f. R. Hertwig. l. Bd. Jena. 1910.

85. Schaxel, J., Die Leistungen dèr Zellen bei der Entwicklung der Hetazoen. Jena. 1915.

86. Schiller, J., Beiträge zur Entwicklungsgeschichte und Physiologie des pflanzl. Zellkernes. Jahrb. f. wiss. Bot. Bd. 49. 1911.

87. Schmidt, E. W., Das Verhalten der Spirogyrazellen nach Einwirkung hoher Zentrifugalkräfte. Ber. d. d. bot. Ges. Bd. 32. 1914.

88. Schmitz, Fr., Die Chromatophoren der Algen. Bonn. 1882.

89. - Beiträge zur Kenntnis der Chromatophoren. Jahrb. f. wiss. Bot. Bd. 15. 1884.

90. Schrammen, T. R., Uber die Einwirkung von Temperaturen auf die Zellen des Vegetationspunktes v. Vicia faba. Verhandl. naturh. Verein. preuß. Rheinlande. Bd. 59. 1902.

91. Schröder, B., Zur Charakteristik des Phytoplanktons temperierter Meere. Ber. d. d. bot. Ges. Bd. 24. 1906.

92. Schultz, M., Beiträge zu einer Algenflora der Umgebung von Greifswald. Dissertat. Greifswald. 1914.

93. Schwarz, Fr., in Cohns Beitr. z. Biol. d. Pflanzen. Bd. 4, 5. 1884, 1892.

94. Senn, G., Die Gestalt- und Lageveränderungen der Pflanzenchromatophoren. Leipzig. 1908.

95̃. Sirodot, J., Les Batrachospermes. Paris. 1884. (zit. nach Stahl.)

96. Stahl, E., Zur Biologie des Chlorophylls. Jena. 1909.

97. Steuer, A., Planktonkunde. Leipzig. 1910.

98. Strasburger, E., Histologische Beiträge. Bd. 2. 1889. Über das Wachstum vegetabil. Zellhäute.

99. Techet, $K$., Verhalten einiger mariner Algen bei Änderung des Salzgehaltes. Österr. bot. Zeitschr. Bd. 54. 1904.

100. - Sur talune forme aberranti di Alghe marine allevante in colture artificiali. Nuova Notarisia. Bd. 19. 1908. (Ref.)

101. Tröndle, Der experimentelle Einflu $B$ von Licht und Temperatur auf die Permeabilität der Plasmahaut. Jahrb. f. wiss. Bot. Bd. 48. 1910.

102. - Der Nukleolus von Spirogyra und die Chromosomen der höheren Pflanzen. Zeitschr. f. Bot. Bd. 4. 1912.

103. Ursprung u. Blum, Der EinfluB der Außenbedingungen auf den osmotischen Wert. Ber. d. d. bot. Ges. Bd. 34. 1915.

104. Verworn, M, Allgemeine Physiologie. Jena. 1909.

105. Vries, H. de, Untersuchungen über die mechanische Ursache der Zellstrekkung. Leipzig. 1877.

106. - U'ber die inneren Vorgänge bei dem Wachstumsvorgange mehrzelliger Organe. Bot. Zeitg. 1879. 
107. Vries, H. de, Eine Methode zur Analyse der Turgorkraft. Jahrb. f. wiss. Bot. Bd. 14. 1884 .

108. - Über die Kontraktion der Chlorophyllbänder bei Spirogyra. Ber. d. d. bot. Ges. Bd. 7. 1889.

109. Wasniewski, J., Der Einfluß der Temperatur, des Lichtes und der Ernährung mit Stickstoff und Mineralstoffen auf den Stoffwechsel in den Keimpflanzen des Weizens. Bull. Acad. Cracovie. Ser. B. Sc. nat. 1914.

110. Watson, C. H., The structure and relation of the Plastids. Contrib. Bot. Lab. Cniv. Pennsylvania. Vol. 2. 1904.

111. Went, Die Vermehrung der normalen Vakuolen durch Teilung. Jahrb. f. wiss. Bot. Bd. 19. 1888.

112. Wille, X., Algologische Untersuchungen an der biolog. Station zu Dront. heim, I-V.II. Kgl. Norskc. Vid. Selksk. Skrifter. 1906. (Ref.)

113. Wisselingh, C. v., Über die Kernteilung bei Spirogyra. Flora. Bd. 87. 1900.

114. - Über abnorme Kernteilung. V. Beitrag zui Kenntnis der Karyokinese. Bot. Zeitg. 1903.

115. - Zur Physiologie der Spirogyrazelle. Beitr. z. bot. Zentrbl. Bd. 24. 1909.

116. Wortmann, Beitrag zur Physiologie des Wachstums. Bot. Zeitg. 1889.

117. Zacharias, E., C̈ber den Nukleolus. Bot. Zeitg. 1885.

118. - Über die Zelle der Cyanophyceen. Bot. Zeitg. 1890.

119. Zimmermann, Jorphologie und Physiologie des pflanzl. Zellkernes. 1896.

\section{Tafelerklärung.}

Sämtliche Präparate in Chromessigsäure fixiert, mit Hämalaun gefärbt und in Glycerin eingeschlossen.

\section{Tafel XVI.}

Abb. 1-10. Vergrößerung etwa 300fach. Objekt. 5, Ocular 4. (Reichert).

Abb. 1-4. Spirogyra tenuissima Kütz. Abb. 1 Kältematerial am 21. II. gesammelt, Abb. 2-1 verschiedene Stadien der Veränderung bei 4tägiger Kultur bei $30^{\circ} \mathrm{C}$.

Abb. 5, 6. Spirogyra varians Kütz. Abb. 5. Kältematerial am 21. II. gesammelt; Abb. 6. Kultur bei $30^{\circ} \mathrm{C}$ nach 4 Tagen.

Abb. 7-1l. Spirogyra grevilleana (Hass.) Kütz. Abb. 7, 8. Zellen mit ein bzw. zwei Chromatophoren als Typus des Kältematerials, gesammelt am 4. III.; Abb. 9, 10. Zellen mit ein bzw. zwei Chromatophoren nach 4 Tagen Kultur bei $30^{\circ} \mathrm{C}$. (Die abgeschnürten Plasmaklümpchen sind gut erkennbar.) Abb. 11. Teil eines Chromatophors der Abb. 10 bei stärkerer Vergrößerung (830fach, homog. Im. 1/12, Ocul. 4), um die vakuolisierten Plasmakugeln zu zeigen.

Abb. 12. Spirogyra nitida Link, Zerfall der Chromatophoren nach 3tägiger Kultur in $30^{\circ} \mathrm{C}$ u. 1 Tag Kultur bei $40^{\circ} \mathrm{C}$. Vergrößerung 70fach. Objekt. 3, Ocul. 4.

Abb. 13, 14. Zygnema affine Kütz. Vergrößerung 350fach, Objekt. 5, Ocul. 4. Abb. 13. Kältematerial (Chromatophor mit sohwacher Reizkontraktion); Abb. $1 \pm$ nach Itägiger Kulturdauer bei $28^{\circ} \mathrm{C}$, Kontraktion und Schwund von Chromatophoren und Plasmafäden.

Abb. 15, 16. Hougeotia scalaris Hass. Vergrößerung 460fach, homog. Im. 1/12, Ocul. 2. Abb. 15 Kältematerial gesammelt am 21. II.; Abb. 16 nach einer 4tägigen Kulturdauer bei $30^{\circ} \mathrm{C}$.

Abb. 17, 18. Desmidium Swartzii Ag. Vergrößerung 830fach, homog. Im. 1/12, Ocul. 4. Abb. 17 Kältematerial (20. III.); Abb. 18 nach 4tägiger Kultur bei $31^{\circ} \mathrm{C}$. 
den Einfluß höherer Temperatur auf Morphologie und Cytologie der Algen. 641

Abb. 19-21. Oedogonium spec. Vergrößerung 460fach, homog. Im. 1/12, Ocul.2. Abb. 19 Kältematerial (20. III.) mit reichlichem Stärkegehalt; Abb. 20, 21 nach 3tägiger Kultur bei $30^{\circ} \mathrm{C}$ verschieden weitgehende Reduktion von Stärke, Chromatophor u. Plasmasubstanz.

Abb. 22, 23. Microspora stagnorum (Kütz.) Lagerh. Vergrößerung 830fach, homog. Im. 1/12, Ocul. 4. Abb. 22 Kältematerial (26. II.); Abb. 23 nach 2tägiger Kultur bei $30^{\circ} \mathrm{C}$.

\section{Tafel XVIr.}

Abb. 24-31. Vergrößerung 830fach, homog. Im. 1/12, Ocul. 4.

Abb. 24, 25. Ulothrix zonata Kützg. Abb. 24 Kältematerial (20. III.); Abb. 25 nach Itägiger Kultur bei $31^{\circ} \mathrm{C}$, Degeneration von Chromatophor u. Plasma.

Abb. 26, 27. Stigeoclonium spec. Abb. 26 Kältematerial (4. III.); Abb. 27 nach 2tägiger Kultur in $31^{\circ} \mathrm{C}$.

Abb. 28, 29. Tabellaria fenestrata Kützg. Abb. 28 Kältematerial (20. III.); Abb. 29 nach 2tägiger Kultur bei $31^{\circ} \mathrm{C}$ (zufällig ist die Größe der photographierten Zellen eine verschiedene in Wärme u. Kälte).

Abb. 30, 3l. Diatoma hiemale (Lyngb.) Kützg. Abb. 30 Kältematerial (20. III.); Abb. 31 nach 1 tägiger Kultur bei $23^{\circ} \mathrm{C}$.

Abb. 32, 33. Cymbella spec. Vergrößerung 480fach, homog. Im. 1/12, Ocul. 2. Abb. 32. Kältematerial (20. III.); Abb. 33 nach 3tägiger Kulturdauer bei $31^{\circ} \mathrm{C}$.

Abb. 34, 35. Synedra spec. Vergrößerung 590fach, homog. Im. 1/12, Ocul. 2. Abb. 34. Kältematerial (20. III.); Abb. 35 nach ltägiger Kultur bei $31^{\circ} \mathrm{C}$.

Abb. 36, 37. Navicula perpusilla Grun. Vergrößerung 830fach, homog. Im. 1/12, Ocul. 4. Abb. 36. Kältematerial (20. IIT.); Abb. 37 nach Itägiger Kultur bei $31^{\circ} \mathrm{C}$.

\section{Oscillatoria princeps Vauch.}

Abb. 38, 39. Vergrößerung 830fach, homog. Im. 1/12, Ocul. 4 (um den allgemeinen Habitus und seine Veränderung in hoher Temperatur zu zeigen). Abb. 38 gesammelt bei $7^{\circ} \mathrm{C}$; Abb. 39 12stunden Kultur bei $36^{\circ} \mathrm{C}$.

Abb. 40-43. Vergrößerung 960 fach, homog. Im. $1 / 12$, Ocul. 4 (um die feineren cytologischen Details zu zeigen).

Abb. 40, 41. Kältematerial $\left(7^{\circ} \mathrm{C}\right)$. Abb. 40 typische Gestalt der überwiegenden Mehrzahl der Fäden; Abb. 41 seltenes Bild mit großem Reichtum des Fadens an Zentralkörnerm, die an den Querwänden liegen.

Abb. 42, 43. Nach 12stündiger Kultur in $36^{\circ} \mathrm{C}$. Abb. 42 Beschaffenheit der Mehrzahl der Fäden. Feinwabiger Bau des im großen und ganzen ziemlich gleichartigen Zellinhaltes, ohne gröbere Einschlüsse; Abb. 43 selteneres Bild, stärke und grobe an Vakuolisierung grenzende Alveolarstruktur. Zentralkörper (Kern) als dunkleres Gebilde in der Zellmitte erkennbar. Keine gröberen Einschlüsse.

\section{Tafel XVIII.}

Sämtliche Zeichnungen mit Tusche und Hilfe des Zeichenapparates nach Hämalaunpräparaten entworfen. (Nur Abb. 47 nach einem Boraxkarminpräparat.)

Abb. 44-52. Vergrößerung 2000fach, homog. Im. 1/12, Comp. Ocul. 12.

Abb. 44-46. Spirogyra tenuissima Kützg. um die Veränderung der Struktur der Chlorophyllbänder, des Kernes und die Chromatinemission ( $A$ bb. 45) zu zeigen. Abb. 44 Kältematerial; Abb. 45 u. 46, 4tägige Kultur bei $30^{\circ}$ C. Chromatinemission (schwarze Körner), Verteilung der Chromatinkörner in der Zelle. Erschöpfung des Kernes und starke Vakuolisation des Nukleolus (Abb. 46), 
Abb. 47, 48. Spirogyra nitida Link. Kerne, Veränderung ihrer Struktur in der Wärme. Abb. 47. Kältekultur $\left(5^{\circ} \mathrm{C}\right)$; Abb. 48. Wärmekultur (3 Tage in $30^{\circ} \mathrm{C}$, darauf 1 Tag in $40^{\circ} \mathrm{C}$ ), Vergröberung der Chromatinstruktur und Chro. matinemission auf dem Wege der Plasmafäden.

Abb. 49, 50. Spirogyra grevilleana (Hass.) Kützg. Abb. 49 Kältematerial, Stück eines mit Stärke vollgestopften Chromatophors; Abb. 50 4tägige Wärmekultur $\left(31^{\circ} \mathrm{C}\right)$, Chromatinemission aus dem Kern, Abnahme seines Chromatingehaltes, veränderte Chromatophorenbeschaffenheit (Stärke vollständig verbraucht).

Abb. 51, 52. Mougeotia scalaris Hass. Abb. 51 Kältematerial; Abb. 52 4tägige Kultur in $30^{\circ} \mathrm{C}$.

Abb. 53, 54. Protococcus olivaceus Rabh. Vergrößerung 2700fach, homog. Im. 1/12, komp. Ocul. 18. Abb. 53 Kältematerial; Abb. 543 tägige Kultur in $30^{\circ} \mathrm{C}$.

Abb. 55, 56. Microspora stagnorum (Ktzg.) Lagerh. Vergrößerung 2000fach, homog. Im. 1/12, komp. Ocul. 12. Abb. 55 Kältematerial, mehrere untereinander anastomosierende Chromatophorenbänder; Abb. 56 nach 2tägiger Kultur bei $30^{\circ} \mathrm{C}$. Chromatophoren besond. in der oberen Zelle vollkommen reduziert. Zellinhalt nur mehr eine spongiöse plasmatische Masse u. Zellsaft.

Abb. 57, 58. Stigeoclonium spec. Vergrößerung 2700fach, homog. Im. 1/12, komp. Ocul. 18. Abb. 57 Kältematerial (Kern mit vielen, sich verzweigenden Fortsätzen und feiner Chromatinstruktur); Abb. 58 nach 2tägiger Kultur in $31^{\circ} \mathrm{C}$. (Kern hat sich kugelig kontrahiert, Zusammenballung des Chromatins.) 